\title{
Retrieval techniques for airborne imaging of methane concentrations using high spatial and moderate spectral resolution: application to AVIRIS
}

\author{
A. K. Thorpe ${ }^{1,2}$, C. Frankenberg ${ }^{2}$, and D. A. Roberts ${ }^{1}$ \\ ${ }^{1}$ Department of Geography, University of California, Santa Barbara, Santa Barbara, California, USA \\ ${ }^{2}$ Jet Propulsion Laboratory, California Institute of Technology, Pasadena, California, USA \\ Correspondence to: A. K. Thorpe (akthorpe@geog.ucsb.edu)
}

Received: 4 September 2013 - Published in Atmos. Meas. Tech. Discuss.: 26 September 2013

Revised: 18 December 2013 - Accepted: 3 January 2014 - Published: 10 February 2014

\begin{abstract}
Two quantitative retrieval techniques were evaluated to estimate methane $\left(\mathrm{CH}_{4}\right)$ enhancement in concentrated plumes using high spatial and moderate spectral resolution data from the Airborne Visible/Infrared Imaging Spectrometer (AVIRIS). An iterative maximum a posteriori differential optical absorption spectroscopy (IMAP-DOAS) algorithm performed well for an ocean scene containing natural $\mathrm{CH}_{4}$ emissions from the Coal Oil Point (COP) seep field near Santa Barbara, California. IMAP-DOAS retrieval precision errors are expected to equal between 0.31 to $0.61{\mathrm{ppm} \mathrm{CH}_{4}}$ over the lowest atmospheric layer (height up to $1.04 \mathrm{~km}$ ), corresponding to about a 30 to $60 \mathrm{ppm}$ error for a $10 \mathrm{~m}$ thick plume. However, IMAP-DOAS results for a terrestrial scene were adversely influenced by the underlying land cover. A hybrid approach using singular value decomposition (SVD) was particularly effective for terrestrial surfaces because it could better account for spectral variability in surface reflectance. Using this approach, a $\mathrm{CH}_{4}$ plume was observed extending $0.1 \mathrm{~km}$ downwind of two hydrocarbon storage tanks at the Inglewood Oil Field in Los Angeles, California (USA) with a maximum near surface enhancement of $8.45 \mathrm{ppm}$ above background. At COP, the distinct plume

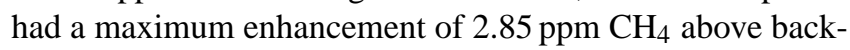
ground, and extended more than $1 \mathrm{~km}$ downwind of known seep locations. A sensitivity analysis also indicates $\mathrm{CH}_{4}$ sensitivity should be more than doubled for the next generation AVIRIS sensor (AVIRISng) due to improved spectral resolution and sampling. AVIRIS-like sensors offer the potential to better constrain emissions on local and regional scales,
\end{abstract}

including sources of increasing concern like industrial point source emissions and fugitive $\mathrm{CH}_{4}$ from the oil and gas industry.

\section{Introduction}

Atmospheric methane $\left(\mathrm{CH}_{4}\right)$ is a long-lived greenhouse gas with an instantaneous radiative forcing 21 times greater than carbon dioxide $\left(\mathrm{CO}_{2}\right)$ on a per molecule basis (IPCC, 2007). In the late preindustrial Holocene (1000 to 1800 A.D.), mean concentrations were $695 \mathrm{ppb}$ (Etheridge et al., 1998) and global concentrations have increased to around $1800 \mathrm{ppb}$ in 2013 (NOAA, 2013). While anthropogenic sources made up an estimated 4 to $34 \%$ of pre-industrial emissions (IPCC, 2007; Houweling et al., 2000), between 60 and $70 \%$ of emissions are presently anthropogenic (Lelieveld et al., 1998). Furthermore, ice core records have indicated $\mathrm{CH}_{4}$ concentrations are closely tied to atmospheric temperature records, while present-day concentrations have not been observed for the previous $420000 \mathrm{yr}$ (Wuebbles and Hayhoe, 2002).

While the global $\mathrm{CH}_{4}$ budget is relatively well constrained $\left(550 \pm 50 \mathrm{Tg} \mathrm{CH}_{4} \mathrm{yr}^{-1}\right)$, there is considerable uncertainty regarding partitioning between individual natural and anthropogenic source types and locations (IPCC, 2007). Major sources of anthropogenic $\mathrm{CH}_{4}$ emissions include the energy, industrial, agricultural, and waste management sectors. In the United States, $50 \%$ of anthropogenic $\mathrm{CH}_{4}$ emissions are from the energy sector, including natural gas and oil systems, 
coal mining, and stationary/mobile combustion (EPA, 2011). Global fugitive $\mathrm{CH}_{4}$ emissions from natural gas and oil systems are of increasing concern, estimated at 1354.42 million metric tonnes $\mathrm{CO}_{2} \mathrm{E} \mathrm{yr}^{-1}\left(64.50 \mathrm{Tg} \mathrm{CH}_{4} \mathrm{yr}^{-1}\right)$ and expected to increase $35 \%$ by 2020 (EPA, 2006). Recent studies also suggest official inventories are underestimated, for example, top-down estimates indicate fugitive $\mathrm{CH}_{4}$ emissions are between 2.3 and $7 \%$ of $\mathrm{CH}_{4}$ produced annually for the Denver-Julesburg Basin, Colorado (Petron et al., 2012). In the Los Angeles Basin, $\mathrm{CH}_{4}$ emissions appear underestimated (Wunch et al., 2009) and unaccounted sources appear to be fugitive and natural $\mathrm{CH}_{4}$ emissions (Wennberg et al., 2012).

Significant natural $\mathrm{CH}_{4}$ sources include wetlands, termites, and geological seeps (IPCC, 2007). Globally, geological seeps are highly uncertain but estimated to contribute between 20 to $40 \mathrm{Tg} \mathrm{CH}_{4} \mathrm{yr}^{-1}$ for terrestrial environments (Etiope et al., 2009) and about $40 \mathrm{Tg} \mathrm{CH}_{4} \mathrm{yr}^{-1}$ for marine seepage (Kvenvolden and Rogers, 2005). In addition, increased surface and ocean temperatures associated with global warming may increase $\mathrm{CH}_{4}$ emissions from melting permafrost (Woodwell et al., 1998) and $\mathrm{CH}_{4}$ hydrate destabilization (Kvenvolden, 1988).

\section{Airborne measurements of $\mathrm{CH}_{4}$}

Aircraft measurements of gas concentrations are useful because they offer the potential to measure local/regional variations in gas concentrations and complement ongoing efforts at coarser spatial resolutions, such as spaceborne sensors. These airborne measurements can improve greenhouse gas emissions inventories and offer the potential for detection and monitoring of emissions (NRC, 2010).

Research and commercial aircraft equipped with in situ gas measurement provides some sense of $\mathrm{CH}_{4}$ variability at local and regional scales (ARCTAS, 2010; Schuck et al., 2012). The nadir-viewing Fourier transform spectrometer (FTS) included as part of the NASA Carbon in Arctic Reservoirs Vulnerability Experiment (CARVE) (Miller and Dinardo, 2012) and spectrometers like MAMAP (Methane Airborne MAPper) (Gerilowski et al., 2011) also offer the potential to measure local emissions. For example, MAMAP detected elevated $\mathrm{CH}_{4}$ concentrations from coal mine ventilation shafts near Ibbenbüren, Germany, allowing for an inversion estimate that agreed closely with emission rates reported from mine operators (Krings et al., 2013). However, these non-imaging spectrometers have a small field of view (FOV) and are limited to flying transects across local gas plumes rather than mapping plumes in their entirety.

By combining large image footprints and fine spatial resolution, airborne imaging spectrometers are well suited for mapping local $\mathrm{CH}_{4}$ plumes. The Airborne Visible/Infrared Imaging Spectrometer (AVIRIS) has a $34^{\circ} \mathrm{FOV}$ and measures reflected solar radiance at the nadir viewing geometry across 224 channels between 350 and $2500 \mathrm{~nm}$ (Green et al., 1998). Strong $\mathrm{CH}_{4}$ absorption features present between 2000 and $2500 \mathrm{~nm}$ can be observed at a $10 \mathrm{~nm}$ spectral resolution and full width half maximum (FWHM). These absorptions are clearly shown in Fig. 1 by transmittance spectra calculated for $\mathrm{CH}_{4}$ using Modtran 5.3 (Berk et al., 1989), parameterized for a mid-latitude summer model atmosphere and nadir-looking sensor at $8.9 \mathrm{~km}$ altitude. High resolution transmittance is shown in red in Fig. 1a and convolved to AVIRIS wavelengths in Fig. 1b, while water vapor $\left(\mathrm{H}_{2} \mathrm{O}\right)$ transmittance has been included in blue to indicate spectral overlap with $\mathrm{CH}_{4}$.

These shortwave infrared (SWIR) absorptions have permitted mapping of concentrated gas plumes in both marine and terrestrial environments using AVIRIS. For bright sun glint scenes at the Coal Oil Point (COP) marine seep field in the Santa Barbara Channel, California, Roberts et al. (2010) developed a spectral residual approach between 2000 and $2500 \mathrm{~nm}$ and Bradley et al. (2011) a band ratio technique using the $2298 \mathrm{~nm} \mathrm{CH}_{4}$ absorption band and $2058 \mathrm{~nm}$ carbon dioxide $\left(\mathrm{CO}_{2}\right)$ absorption band. However, these techniques are not suited for terrestrial locations that have lower albedos and have spectral structure in the SWIR. A cluster-tuned matched filter (CTMF) technique is capable of mapping $\mathrm{CH}_{4}$ plumes from marine and terrestrial sources (Thorpe et al., 2013) as well as $\mathrm{CO}_{2}$ from power plants (Dennison et al., 2013); however, this method does not directly quantify gas concentrations.

The logical next step is to focus on quantification and uncertainty estimation using techniques originally developed for satellite sensors such as differential optical absorption spectroscopy (DOAS) (Platt, 1994). In this study, an iterative maximum a posteriori differential optical absorption spectroscopy (IMAP-DOAS) (Frankenberg et al., 2005c) algorithm was adapted for gas detection in AVIRIS imagery. In addition, a hybrid approach using singular value decomposition (SVD) and IMAP-DOAS was also developed as a complementary method of quantifying gas concentrations within complex AVIRIS scenes.

\section{Basic principles of IMAP-DOAS}

Retrieval algorithms for absorbing species in the SWIR require radiative transfer modeling of solar radiation along the light path to the sensor and must be capable of simulating changes in radiation due to differing abundances of $a b-$ sorbers. These techniques permit comparison of simulated at sensor radiance with a known abundance of absorbers with measured radiance provided by the sensor. Differential optical absorption spectroscopy (DOAS) (Platt, 1994) is one approach that has been used for a number of applications, including ground-based (Stutz et al., 2010), satellite (Schneising et al., 2012), and airborne measurement (Gerilowski et al., 2011). The underlying principle of DOAS 
a)

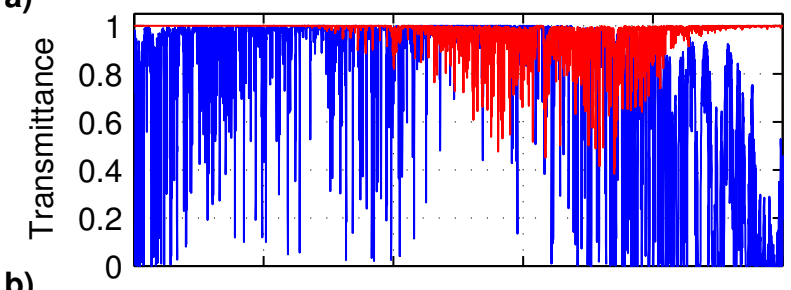

b)

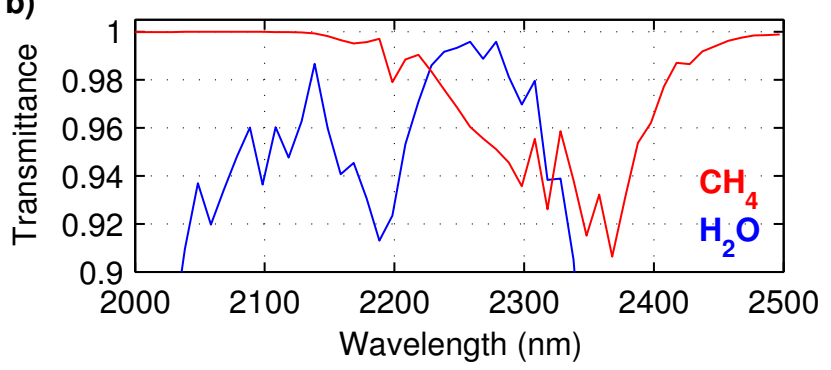

Fig. 1. (a) High resolution $\mathrm{CH}_{4}$ and $\mathrm{H}_{2} \mathrm{O}$ transmittance. (b) Transmittance convolved to the $10 \mathrm{~nm}$ AVIRIS spectral resolution.

is to isolate higher frequency features resulting from gas absorptions from lower frequency features that include surface reflectance as well as Rayleigh and Mie scattering (Bovensmann et al., 2011). To do so, a polynomial function accounting for low-frequency features is often used, which is described in further detail in Sect. 5.2.

Classical DOAS (Platt, 1994) is based on the LambertBeer law and describes the relationship between incident intensity for the vertical column $\left(I_{0}(v)\right)$ and measured intensity $(I(v))$ after passing through a light path $(\mathrm{d} s)$ containing an absorber:

$I(v)=I_{0}(v) \cdot \exp \left(-\int \sigma(v, p, T) c(s) \mathrm{d} s\right)$.

Each absorber has an associated absorption cross section $(\sigma)$ and number concentration of the absorber $(c(s)$, molecules $\mathrm{m}^{-3}$ ). Equation (1) is wavelength dependent and the absorption cross section varies with temperature $(T)$ and pressure $(p)$. If the atmospheric absorption features are fully resolved by the instrument and only weak absorbers are present, Eq. (1) can be linearized with respect to slant column density $S$ :

$$
\begin{aligned}
\boldsymbol{\tau} & =\ln \left(\frac{I_{0}(v)}{I(v)}\right) \approx \sigma(v, \bar{p}, \bar{T}) \cdot \int c(s) \mathrm{d} s \\
& =\sigma(v, p, T) \cdot S
\end{aligned}
$$

where measured optical density $(\boldsymbol{\tau})$ is proportional to the product of the absorption cross section and the retrieved $S$, the path integral of the concentration of the absorber along the light path. $S$ is related to the vertical column density $(V)$, the integral of the concentration along the vertical from the surface to the top of atmosphere, by way of the air mass factor $(A)$, where $A=S / V$. In the SWIR, scattering in the atmosphere is generally low (Buchwitz and Burrows, 2003; Dufour and Breon, 2003) and for our applications, the impact of scattering is far lower than the retrieval precision error. Thus, it can be neglected and $A=$ $1 / \cos (\mathrm{SZA})+1 / \cos$ (LZA), where SZA is the solar zenith angle and LZA is the line-of-sight zenith angle. However, scattering could become non-negligible in some examples, including industrial plumes that contain heavy aerosol loading or dark surfaces with low SZA.

For a single absorber measured with a moderate spectral resolution and ignoring scattering, a theoretical slant optical density $\left(\boldsymbol{\tau}_{\lambda}^{\text {meas }}\right)$ can be calculated as follows:

$\boldsymbol{\tau}_{\lambda}^{\text {meas }}(x)=-\ln \left(<\exp \left(-x \cdot A \cdot \boldsymbol{\tau}_{\lambda}^{\mathrm{ref}}\right)>\right)$

where the reference vertical optical density $\left(\boldsymbol{\tau}_{\lambda}^{\text {ref }}\right)$ is scaled by both the air mass factor $(A)$ as well as a retrieved scaling factor $(x)$ and $<\cdot>$ denotes convolution with the instrument function. In addition to scaling $\tau_{\lambda}^{\text {meas }}, x$ can be used to estimate gas concentrations relative to those concentrations present within the reference atmosphere.

However, moderate spectral resolution spectrometers cannot fully resolve individual absorption lines and must convolve light using an instrument line shape (ILS) function wider than individual absorption lines. If absorptions are strong, this results in a nonlinear relationship between the measured optical density ( $\boldsymbol{\tau})$ and the retrieved slant column density of the absorber $(S)$ shown in Eq. (2) (Frankenberg et al., 2005c). In the $2300 \mathrm{~nm}$ region, strong $\mathrm{H}_{2} \mathrm{O}$ and $\mathrm{CH}_{4}$ absorption lines are saturated within their line cores. These factors render Eq. (2) nonlinear and cause classical DOAS algorithms to fail, requiring iterative procedures to account for the induced nonlinearity.

To address the strong sensitivity of the shape of spectral absorption lines to temperature and pressure as well as unresolved absorption lines (Platt and Stutz, 2008), the weighting function modified differential optical absorption spectroscopy (WFM-DOAS) retrieval algorithm was developed (Buchwitz et al., 2000). WFM-DOAS introduced weighting functions to linearize the problem of a linearization point in the expected slant column density using vertical profiles of all absorbers as well as pressure and temperature profiles. It has been used to estimate column amounts of $\mathrm{CO}$ (carbon monoxide), $\mathrm{CO}_{2}$, and $\mathrm{CH}_{4}$ using Scanning Imaging Absorption Spectrometer for Atmospheric Chartography (SCIAMACHY) data, which have a spectral resolution between 0.2 and $1.5 \mathrm{~nm}$ (Buchwitz et al., 2005). A modified WFM-DOAS algorithm is used with the airborne MAMAP, which has a SWIR grating spectrometer for measuring $\mathrm{CH}_{4}$ and $\mathrm{CO}_{2}$ absorptions between 1590 and $1690 \mathrm{~nm}$ with a $0.82 \mathrm{~nm}$ FWHM (Gerilowski et al., 2011). In addition to detecting elevated $\mathrm{CH}_{4}$ concentrations from coal mines (Krings et al., 2013), MAMAP has been used to measure both $\mathrm{CH}_{4}$ and $\mathrm{CO}_{2}$ emissions from power plants (Krings et al., 2011). 
Frankenberg et al. (2005c) developed the IMAP-DOAS algorithm, which uses optimal estimation theory to adjust the slant column densities of multiple gasses until total optical density fits the observed measurement. IMAP-DOAS considers the shape of the spectral absorption lines, as they vary with temperature and pressure in multiple atmospheric layers, and convolves absorption lines using the instrument line shape function. This technique is based on a simple nonscattering radiative transfer scheme, which allows very fast retrievals and is well suited for processing of AVIRIS imagery. For the $2300 \mathrm{~nm}$ range, where Rayleigh scattering can be ignored and aerosol optical depths are low, this assumption in IMAP-DOAS is valid, given errors induced by neglected scattering in AVIRIS scene are typically much lower ( 0 to $2 \%$ ) than precision errors in retrieved column estimates $(>3 \%)$. Additional details of the IMAP-DOAS algorithm and retrieval method are presented in Sect. 5.

While IMAP-DOAS has been used with SCIAMACHY data to estimate global column-averaged mixing ratios for $\mathrm{CH}_{4}$ (Frankenberg et al., 2005a, 2011) and CO (Frankenberg et al., 2005b), this study is the first to use aircraft measurements. Moderate resolution spectrometers like AVIRIS require large fitting windows, and disentangling surface spectral features from atmospheric absorptions becomes more complicated using fitting routines such as WFM-DOAS and IMAP-DOAS. High resolution spectrometers can circumvent this problem since atmospheric absorption lines are narrow and surface properties, which vary on a scale greater than 5 to $10 \mathrm{~nm}$, can be fitted using polynomial functions. In this case, reflectance spectra of terrestrial surfaces (not including narrow atmospheric features) can usually be represented by a low order polynomial as a function of wavelength. For the $10 \mathrm{~nm}$ spectral resolution and FWHM of AVIRIS, distinguishing surface features from atmospheric absorptions will be more difficult. Therefore, we developed an alternative hybrid approach using both IMAP-DOAS and SVD of surface reflectance properties at background $\mathrm{CH}_{4}$ concentrations.

\section{Study sites and AVIRIS data}

Two AVIRIS scenes were used in this study, both acquired in California in 2008. The first scene was acquired over the COP marine seep field near Santa Barbara from an $8.9 \mathrm{~km}$ altitude, resulting in an image swath of $\sim 5.4 \mathrm{~km}$ and a ground instantaneous field of view (IFOV) of $\sim 7.5 \mathrm{~m}$. The scene was acquired on 19 June 2008 at approximately 19:55 UTC (12:55 PDT) with a $11.4^{\circ}$ solar zenith resulting in high sun glint. COP is one of the largest natural seeps with total atmospheric $\mathrm{CH}_{4}$ emissions estimated at $100000 \mathrm{~m}^{3}$ day $^{-1}$ (0.024 $\mathrm{Tg} \mathrm{CH}_{4} \mathrm{yr}^{-1}$ ) (Hornafius et al., 1999). A 308 by 191 pixel image subset was used for the IMAP-DOAS and SVD algorithms, covering $3.31 \mathrm{~km}^{2}$ centered on the COP seep field $\left(34^{\circ} 23^{\prime} 46.59^{\prime \prime} \mathrm{N}, 119^{\circ} 52^{\prime} 4.47^{\prime \prime} \mathrm{W}\right)$.
The second scene covered the Inglewood Oil Field, located in Los Angeles in an area that has active oil and gas extraction (DOGGR, 2010). The AVIRIS scene was acquired at approximately 21:12 UTC (14:12 PDT) on 18 September 2008 at $4.0 \mathrm{~km}$ altitude, resulting in a swath width of $\sim 2.7 \mathrm{~km}$, ground IFOV of $\sim 3 \mathrm{~m}$, and a $38.1^{\circ}$ solar zenith. For this scene, a 161 by 172 pixel image subset $\left(0.25 \mathrm{~km}^{2}\right.$ centered at $33^{\circ} 59^{\prime} 28.68^{\prime \prime} \mathrm{N}, 118^{\circ} 21^{\prime} 34.59^{\prime \prime} \mathrm{W}$ ) was selected because it contains a $\mathrm{CH}_{4}$ plume detected using a CTMF technique, with hydrocarbon storage tanks as a probable emission source (Thorpe et al., 2013).

\section{IMAP-DOAS retrieval method}

The IMAP-DOAS retrieval relies on layer optical properties of absorbing species calculated for a realistic temperature/pressure and trace gas concentration profile for a given location. In addition, instrument line shape and flight parameters are used with geometric radiative transfer calculations to simulate at-sensor radiances and Jacobians with respect to trace gas abundances for each atmospheric layer. In the following, we describe input parameters and additional details of the IMAP-DOAS retrieval.

\subsection{IMAP-DOAS input parameters}

For the two 2008 AVIRIS scenes, temperature, pressure, and $\mathrm{H}_{2} \mathrm{O}$ volume mixing ratio (VMR) profiles acquired from the National Centers for Environmental Prediction/National Center for Atmospheric Research (NCEP/NCAR) Reanalysis project were extracted for the appropriate date and time for either location (Kalnay et al., 1996). The NCEP data are provided on a $2.5^{\circ}$ latitude $\times 2.5^{\circ}$ longitude grid every $6 \mathrm{~h}$ with 17 pressure levels between 10 and $1000 \mathrm{mb}$. Prior profiles of $\mathrm{CH}_{4}$ and $\mathrm{N}_{2} \mathrm{O}$ are based on the US standard atmosphere obtained from the radiative transfer models LOWTRAN/MODTRAN (Kneizys et al., 1996). These profiles were scaled to reflect the VMR for $\mathrm{CH}_{4}$ and $\mathrm{N}_{2} \mathrm{O}$ using the 2008 mean VMR provided from the NOAA Mauna Loa station, United States (NOAA, 2013). For both gasses, the percent increase of the 2008 mean VMR compared to the US standard atmosphere at $0 \mathrm{~km}$ altitude was calculated and used to update the VMR up to $25 \mathrm{~km}$ altitude. Finally, we computed vertical optical depths for 10 atmospheric layers at $100 \mathrm{mb}$ intervals between 0 and $1000 \mathrm{mb}$.

For AVIRIS, the strongest $\mathrm{CH}_{4}$ absorptions occur between 2200 to $2400 \mathrm{~nm}$ (Fig. 1). Spectral parameters for $\mathrm{CH}_{4}, \mathrm{H}_{2} \mathrm{O}$, and $\mathrm{N}_{2} \mathrm{O}$ were used from the HITRAN database (Rothman et al., 2009). We used a classical Voigt spectral line shape to calculate $\mathrm{CH}_{4}, \mathrm{H}_{2} \mathrm{O}$, and $\mathrm{N}_{2} \mathrm{O}$ vertical optical densities for each of the 10 atmospheric layers.

Given that the two AVIRIS scenes were acquired at different flight altitudes and SZA, geometric air mass factors (AMF) had to be calculated for each of the 10 layers to 


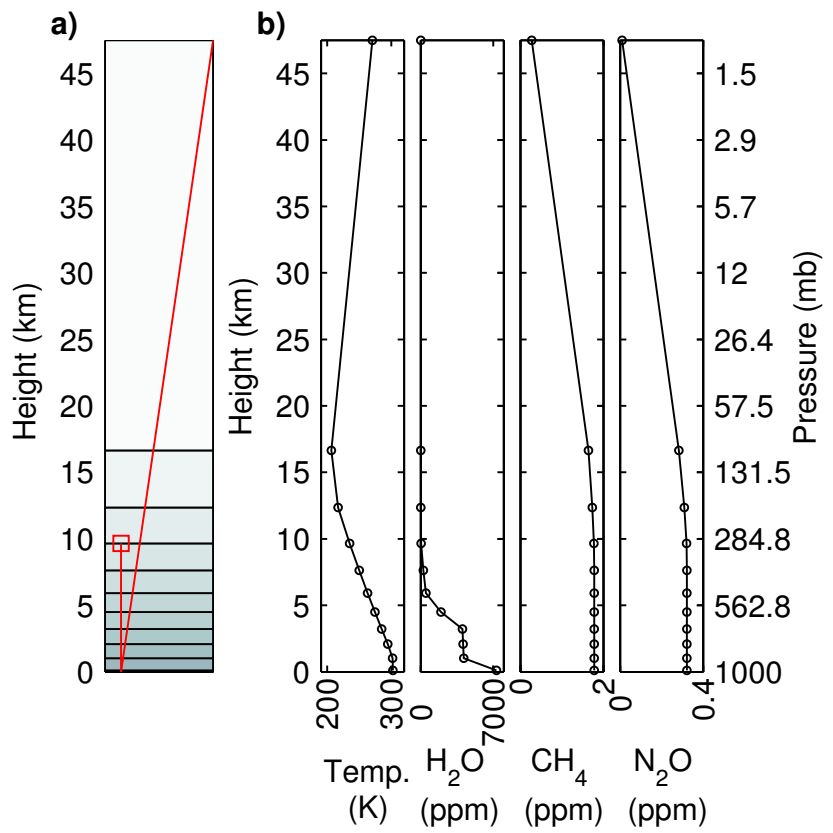

Fig. 2. (a) 10 atmospheric layers were used for retrievals (layer 1 at the top). For the COP scene, the aircraft was placed between layer 3 and 4 (red square). The slant and vertical light paths (red lines) were used to scale optical densities appropriately. (b) Profiles of temperature and VMR of $\mathrm{H}_{2} \mathrm{O}, \mathrm{CH}_{4}$, and $\mathrm{N}_{2} \mathrm{O}$ for the boundaries of each layer (black circles).

account for either one- (above sensor) or two-way (below sensor) transmission through each layer. For example, the COP flight was at $8.9 \mathrm{~km}$ altitude with a solar zenith angle of $11.4^{\circ}$, placing the aircraft approximately at the boundary between atmospheric layer 3 and 4 (Fig. 2). In this simplified setup, the AMF for layers 1 to 3 (above the aircraft) is calculated as $1 / \cos \left(11.4^{\circ}\right)=1.02$, while for layers 4 to 10 , an AMF of $2.02\left(1 / \cos \left(11.4^{\circ}\right)+1 / \cos \left(0.0^{\circ}\right)\right)$ accounts for two-way transmission. Similar calculations were performed for the Los Angeles scene, which was acquired with a SZA of $38.1^{\circ}$ at $4.0 \mathrm{~km}$ altitude, placing the aircraft approximately at the boundary between layer 5 and 6 .

Additional input parameters for the IMAP-DOAS algorithm are shown in Fig. 3, including the AVIRIS radiance data, spectral resolution of the sensor, signal-to-noise ratio (SNR) estimate, and the full width at half maximum of the instrument line-shape (FWHM $=10.42 \mathrm{~nm}$, assuming a Gaussian line-shape). An average FWHM and an average SNR were calculated for bands included within the fitting window, while the high resolution solar transmission spectrum was generated using a solar line list (Geoffrey Toon, personal communication, 2013).

The optimal choice of a fitting window for the IMAPDOAS $\mathrm{CH}_{4}$ retrievals was determined iteratively. We began using all spectral bands between 2100 and $2500 \mathrm{~nm}$ corresponding to strong $\mathrm{CH}_{4}$ absorptions, but observed strong

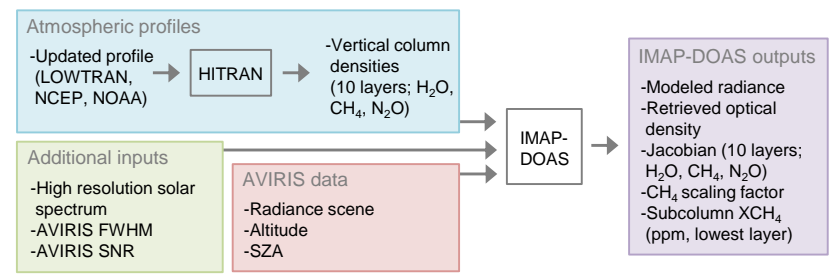

Fig. 3. Processing steps for IMAP-DOAS $\mathrm{CH}_{4}$ retrieval.

correlations with surface features. This is likely related to spectrally smooth convolved transmissions from 2200 to $2300 \mathrm{~nm}$ and above $2370 \mathrm{~nm}$ (Fig. 1b). As we decreased the size of the fitting window to focus on the more highfrequency $\mathrm{CH}_{4}$ features, the spectral variability associated with AVIRIS bands at either end of the fitting window was reduced and results improved. The fitting window selected for this study used 9 bands between 2278 and $2358 \mathrm{~nm}$, including three prominent absorption features visible in $\mathrm{CH}_{4}$ Jacobians shown in Fig. 4a.

\subsection{Forward model and optimal estimation}

Using 10 atmospheric layers and the gasses $\mathrm{CH}_{4}, \mathrm{H}_{2} \mathrm{O}$, and $\mathrm{N}_{2} \mathrm{O}$ results in a state vector with 30 rows $\left(\boldsymbol{x}_{n}\right)$. A forward radiative transfer model at high spectral resolution was used to calculate modeled radiance at each wavelength using the equation below:

$\boldsymbol{F}^{\mathrm{hr}}\left(\boldsymbol{x}_{i}\right)=\boldsymbol{I}_{0}^{\mathrm{hr}} \cdot \exp \left(-\sum_{n=1}^{30} \boldsymbol{A}_{n} \cdot \boldsymbol{\tau}_{n}^{\mathrm{ref}} \cdot \boldsymbol{x}_{n, i}\right) \cdot \sum_{i=0}^{k} a_{k} \lambda^{k}$,

where $\boldsymbol{F}^{\mathrm{hr}}\left(\boldsymbol{x}_{i}\right)$ is the forward modeled radiance at the $i$ th iteration of the state vector, $\boldsymbol{I}_{0}^{\mathrm{hr}}$ is the incident intensity (solar transmission spectrum), $\boldsymbol{A}_{n}$ is the AMF for each $n$ number of atmospheric state vector elements (30 rows, specified for each of the 10 layers and repeated for each gas), $\boldsymbol{\tau}_{n}^{\mathrm{ref}}$ is the reference total optical density for each $\mathrm{n}$ number of atmospheric state vector elements (including optical densities of $\mathrm{CH}_{4}, \mathrm{H}_{2} \mathrm{O}$, and $\mathrm{N}_{2} \mathrm{O}$ ), $\boldsymbol{x}_{n, i}$ is the trace gas related state vector at the $i$ th iteration, which scales the prior optical densities of $\mathrm{CH}_{4}, \mathrm{H}_{2} \mathrm{O}$, and $\mathrm{N}_{2} \mathrm{O}$ in each $n$ layer (30 rows), $a_{k}$ are polynomial coefficients to account for low-frequency spectral variations.

The high resolution modeled radiance is then convolved with the ILS and sampled to the center wavelengths of each AVIRIS spectral band. This results in a low resolution modeled radiance at the $i$ th iteration of the state vector $\left(\boldsymbol{F}^{1 \mathrm{r}}\left(\boldsymbol{x}_{i}\right)\right)$, calculated using a known $\boldsymbol{\tau}_{n}^{\text {ref }}$ scaled by $\boldsymbol{x}_{n, i}$.

In addition to the scaling factors for $\mathrm{CH}_{4}, \mathrm{H}_{2} \mathrm{O}$, and $\mathrm{N}_{2} \mathrm{O}$ in each $\mathrm{n}$ layers $\left(\boldsymbol{x}_{n}\right)$, the state vector contains the spectral shift (not shown here) as well as a low order polynomial function $\left(a_{k}\right)$ to account for the broadband variability in surface albedo (see Frankenberg et al., 2005c). 


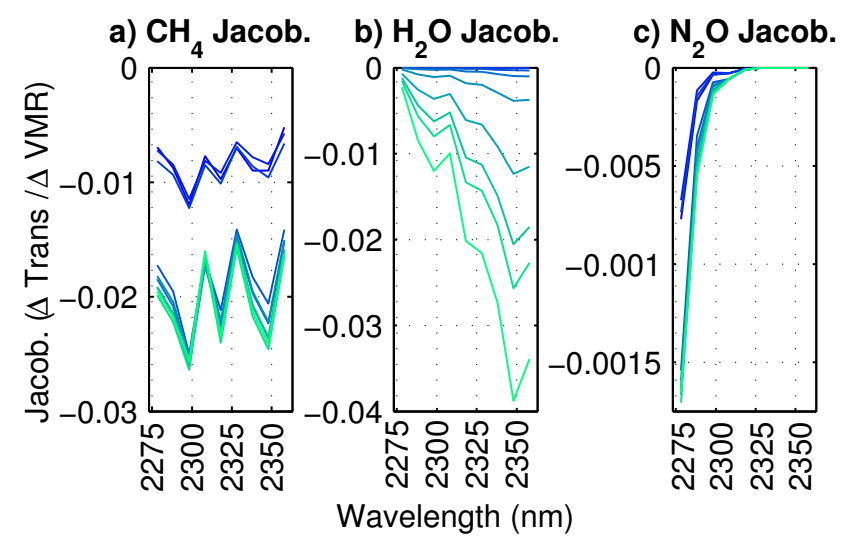

Fig. 4. (a) $\mathrm{CH}_{4}$ Jacobian for each of the 10 atmospheric layers with colors transitioning from dark blue at the highest layer (layer 1) to light green for the lowest layer (layer 10). The $\mathrm{CH}_{4}$ Jacobians with smaller magnitudes (dark blue) are for layers above the flight altitude. The same color scheme is used for the $\mathrm{H}_{2} \mathrm{O}$ Jacobians (b) and $\mathrm{N}_{2} \mathrm{O}$ Jacobians (c).

At each iteration $i$, a Jacobian matrix is calculated where each column represents the derivative vector of the sensor radiance with respect to each element of the state vector $\left(\boldsymbol{x}_{i}\right)$.

$\mathbf{K}_{i}=\left.\frac{\partial \boldsymbol{F}^{\mathrm{lr}}(\boldsymbol{x})}{\partial \boldsymbol{x}}\right|_{\boldsymbol{x}_{i}}$.

The forward model and the Jacobian Matrix can be used to optimize the state vector at the $i$ th iteration as follows (Rodgers, 2000):

$$
\begin{aligned}
& \boldsymbol{x}_{i+1}= \boldsymbol{x}_{\mathrm{a}}+\left(\mathbf{K}_{i}^{T} \mathbf{S}_{\varepsilon}^{-1} \mathbf{K}_{i}+\mathbf{S}_{\mathrm{a}}^{-1}\right)^{-1} \mathbf{K}_{i}^{T} \mathbf{S}_{\varepsilon}^{-1} \\
& \cdot\left[\boldsymbol{y}-\boldsymbol{F}^{1 \mathrm{r}}\left(\boldsymbol{x}_{i}\right)+\mathbf{K}_{i}\left(\boldsymbol{x}_{i}-\boldsymbol{x}_{\mathrm{a}}\right)\right]
\end{aligned}
$$

where $\boldsymbol{x}_{\mathrm{a}}$ is the a priori state vector (30 rows), $\boldsymbol{x}_{i}$ is the state vector at the $i$ th iteration (30 rows), $\mathbf{S}_{\varepsilon}$ is the error covariance matrix, $\mathbf{S}_{\mathrm{a}}$ is the a priori covariance matrix, $\boldsymbol{y}$ is the measured AVIRIS radiance, $\boldsymbol{F}^{1 \mathrm{r}}\left(\boldsymbol{x}_{i}\right)$ is the forward model evaluated at $\boldsymbol{x}_{i}$, and $\mathbf{K}_{i}$ is the Jacobian of the forward model at $\boldsymbol{x}_{i}$.

The a priori state vector was set to 1 for each gas at each layer, while the a priori covariance matrix was set to constrain the fit to the lowest atmospheric layer (height up to $1.04 \mathrm{~km}$ ) where high variance is expected. To achieve this, very tight prior covariances were set for all atmospheric layers except the lowermost one, which is basically unconstrained. This assumption is reasonable given that the COP and Inglewood scenes contain $\mathrm{CH}_{4}$ emission from ground sources that are not expected to extend above this atmospheric layer. $\mathrm{CH}_{4}$ concentrations were calculated by multiplying the $\mathrm{CH}_{4}$ state vector at the last iteration $\left(\mathrm{CH}_{4}\right.$ scaling factor) by the VMR for the lowest layer of the reference atmosphere (Fig. 2).

\section{Basic principles of SVD}

SVD transforms a large number of potentially correlated vectors into a smaller set of uncorrelated (orthogonal) vectors, denoted as singular vectors (Press et al., 2007; Rodgers, 2000). It is closely related to principal component analysis (PCA) and offers the potential for reduced computation time by efficiently summarizing high dimensional data. It has been used in a number of remote sensing applications, including cloud detection using the Michelson Interferometer for Passive Atmospheric Sounding (MIPAS) (Hurley et al., 2009), retrieving aerosol optical densities of mineral dust using the Infrared Atmospheric Sounding Interferometer (IASI), and retrieval of terrestrial chlorophyll fluorescence using the Fourier Transform Spectrometer (FTS) on board the Greenhouse gases Observing SATellite (GOSAT) platform (Guanter et al., 2012).

For this study, we constructed an $m \times n$ matrix $\mathbf{L}$, where $m$ is the number of spectral bands (for the $\mathrm{CH}_{4}$ fit window) and $n$ is the number of radiance spectra in a specific AVIRIS scene. This can be expressed as

$\mathbf{L}=\mathbf{U} \boldsymbol{\Lambda} \mathbf{V}^{T}$,

where the $m \times m$ matrix $\mathbf{U}$ contains the left singular vectors and the $n \times n$ matrix $\mathbf{V}$ contains the right singular vectors in their respective columns. $\boldsymbol{\Lambda}$ is an $m \times n$ rectangular diagonal matrix containing the $m$ singular values of $\mathbf{L}$ on its diagonal. These singular values are essentially eigenvalues that correspond to the $m$ columns of $\mathbf{U}$, which are analogous to eigenvectors. Each of the $n$ columns of $\mathbf{V}$ is essentially a principal component of the scene, with each successive column capturing increasingly less signal variability. Therefore, $\mathbf{L}$ can be recomposed as a linear combination of singular vectors scaled by the singular values (Murtagh and Heck, 1987).

\section{SVD retrieval method}

For each AVIRIS image subset, the radiance scene was first standardized by fitting a first order polynomial to each radiance spectrum and dividing it by the polynomial fit. Next, a mean radiance spectrum was calculated from the standardized data and the IMAP-DOAS retrieval was performed on the mean spectrum to generate the $\mathrm{CH}_{4}$ Jacobian for the lowest layer $\left(\mathbf{K}_{\mathrm{CH}_{4}}\right)$ (Fig. 5). This standardization was performed to ensure that the computed $\mathrm{CH}_{4}$ Jacobian is representative for all pixels; without it, calculations of Jacobians for each continuum level would be required. As an alternative to standardization, a SVD in log-space could be considered since optical depths are linear with respect to changing concentrations in the vicinity of the linearization point.

Using Eq. (7), the SVD was performed on each image subset using the standardized radiance $(m \times n$ matrix $\mathbf{L}$, where $m$ is the number of spectral bands and $n$ is the number of radiance spectra). Due to computing limitations, the economy 


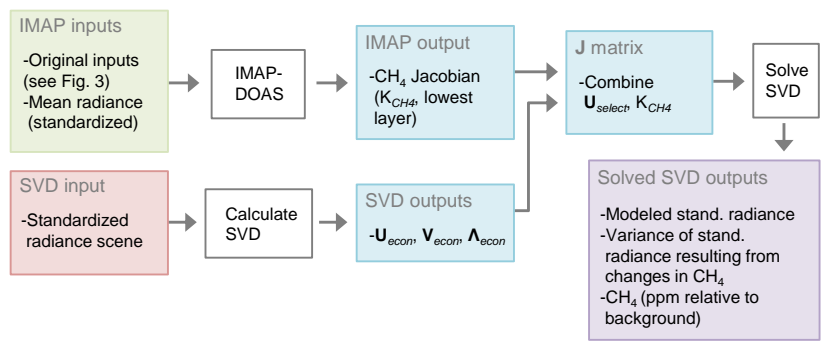

Fig. 5. Processing steps for the SVD retrieval method. The IMAPDOAS retrieval is performed on a mean radiance for the image subset to generate the $\mathrm{CH}_{4}$ Jacobian for the lowest layer. The SVD is used to calculate $\mathbf{U}_{\text {econ }}, \mathbf{V}_{\text {econ }}$, and $\boldsymbol{\Lambda}_{\text {econ }}$, while $\mathbf{U}_{\text {select }}$ is combined with the $\mathrm{CH}_{4}$ Jacobian to generate the $\mathbf{J}$ matrix. $\mathbf{J}$ is used to determine the portion of each radiance spectra associated with the $\mathrm{CH}_{4}$ Jacobian (i.e., absorptions due to $\mathrm{CH}_{4}$ ) and can be used to estimate $\mathrm{CH}_{4}$ concentrations.

version of the SVD was calculated using MATLAB (Mathworks, Natick, Massachusetts, USA). This resulted in $\mathbf{U}_{\text {econ }}$ maintaining a dimension of $m \times m$ (left singular vectors in $m$ columns), but reduced matrix dimensions for $\mathbf{V}_{\text {econ }}$ and $\boldsymbol{\Lambda}_{\text {econ }}(n \times m$ and $m \times m$, respectively).

The first $c$ columns of $\mathbf{U}_{\text {econ }}\left(\mathbf{U}_{\text {select }}\right.$, an $m \times c$ matrix where the optimal selection of $c$ is described below) and the $\mathrm{CH}_{4} \mathrm{Ja}$ cobian $\left(\mathbf{K}_{\mathrm{CH}_{4}}\right.$, an $m \times 1$ matrix) are concatenated to generate a matrix $\mathbf{J}$ (dimensions of $m \times c+1$ ). The basic principle is to reflect the general variability in spectral radiances by a linear combination of the first c eigenvectors and the $\mathrm{CH}_{4}$ Jacobian, which relates to deviations from background concentrations since the background radiance is already modeled using the linear combination of eigenvectors. A similar technique was used to retrieve terrestrial chlorophyll fluorescence using the FTS on board GOSAT (Guanter et al., 2012). The linear combination of eigenvectors is an empirical way to compute the forward model radiance, which can include many detector and surface albedo features that the IMAP-DOAS approach cannot easily handle.

Using linear least squares, we can now find a vector $\boldsymbol{W}$ that minimizes the cost function involving the measured radiance spectra $\boldsymbol{y}$ :

$\|\boldsymbol{y}-\mathbf{J} \boldsymbol{W}\|^{2}$.

$\boldsymbol{W}$ represents the contribution of each column of $\mathbf{J}$ to the measured radiance. The modeled radiance $\boldsymbol{F}$ can be calculated by multiplying $\mathbf{J}$ by the weights $\boldsymbol{W}$ :

$\boldsymbol{F}=\mathbf{J} \boldsymbol{W}$,

resulting in a modeled radiance that can be compared to the measured radiance for each spectrum.

The previous equation can be rewritten as the sum of the background and $\mathrm{CH}_{4}$ component of the radiance as follows:

$\boldsymbol{F}(\boldsymbol{W}, \mathbf{J})=\sum_{k=1}^{c} \mathbf{J}_{k} \cdot \boldsymbol{W}_{k}+\mathbf{J}_{c+1} \cdot \boldsymbol{W}_{c+1}$ where the left term represents the background radiance modeled as a linear combination of the first $c$ eigenvectors of $\mathbf{J}$ $\left(\mathbf{J}_{k}\right)$ multiplied by the corresponding weights $\boldsymbol{W}_{k}$. The right term is the $\mathrm{CH}_{4}$ component of the scene, the product of $\mathbf{J}_{C+1}$ (the $\mathrm{CH}_{4}$ Jacobian, $\mathbf{K}_{\mathrm{CH}_{4}}$ ) and its corresponding weight $\boldsymbol{W}_{c+1}$ (denoted as $\mathrm{RCH}_{4}$ ). In Eq. (10), the fit coefficients are $c$ and $\boldsymbol{W} . \mathrm{RCH}_{4}$ indicates how much of the observed radiance for each spectrum can be associated with the $\mathrm{CH}_{4}$ Jacobian (i.e., changes in absorptions due to $\mathrm{CH}_{4}$ ) and can be used to both estimate $\mathrm{CH}_{4}$ concentrations as well as its uncertainties. Similar to the IMAP-DOAS approach, $\mathrm{RCH}_{4}$ for each pixel is multiplied by the VMR for the lowest layer of the reference atmosphere and results in an estimated $\mathrm{CH}_{4}$ concentration in ppm above/below the average.

The same 9 bands between 2278 and $2358 \mathrm{~nm}$ that made up the IMAP-DOAS retrieval window were initially used for the hybrid SVD approach. In an iterative process, additional bands between 2218 and $2457 \mathrm{~nm}$ were included to better account for high-frequency variation present in the scenes. A portion of the scene was selected for a homogeneous land cover and the standard deviation of the $\mathrm{RCH}_{4}$ results for different fitting windows was calculated. A 16-band fitting window ( 2278 to $2428 \mathrm{~nm}$ ) was selected because it produced the lowest standard deviation in $\mathrm{RCH}_{4}$ and thereby minimized noise in results.

Using these 16 bands, the hybrid SVD retrieval was performed iteratively by increasing the c columns of $\mathbf{U}_{\text {econ }}$ used to generate $\mathbf{U}_{\text {select }}$. This resulted in 16 SVD retrievals, which were assessed by minimizing the standard deviation of the $\mathrm{RCH}_{4}$ results for the portion of the scene selected to represent homogeneous land cover. This technique was used to determine the optimal number of columns of $\mathbf{U}_{\text {econ }}$ to use with the SVD retrieval for the COP and Inglewood scenes.

\section{Results for IMAP-DOAS sensitivity study}

To investigate the expected IMAP-DOAS retrieval errors for the 9-band fitting window between 2278 and $2358 \mathrm{~nm}$, the covariance $\hat{S}$ was calculated using the following equation:

$\hat{S}=\left(\mathbf{K}^{T} \mathbf{S}_{\varepsilon}^{-1} \mathbf{K}+\mathbf{S}_{\mathrm{a}}^{-1}\right)^{-1}$,

where the diagonal of $\hat{S}$ corresponds to the covariance associated with $\mathrm{CH}_{4}, \mathrm{H}_{2} \mathrm{O}$, and $\mathrm{N}_{2} \mathrm{O}$ at each of the 10 atmospheric layers. $\mathbf{S}_{\varepsilon}$ is the error covariance matrix, a diagonal matrix representing expected errors resulting from shot-noise and dark current that is calculated using the SNR for the AVIRIS sensor.

The precision error of the IMAP-DOAS retrieval algorithm is calculated by multiplying the square root of the corresponding diagonal entry of $\hat{S}$ (the standard deviation of the $\mathrm{CH}_{4}$ fit factor) by $1.78 \mathrm{ppm} \mathrm{CH}_{4}$, the 2008 mean VMR provided from the NOAA Mauna Loa station, United States (NOAA, 2013). These errors were calculated for a number 


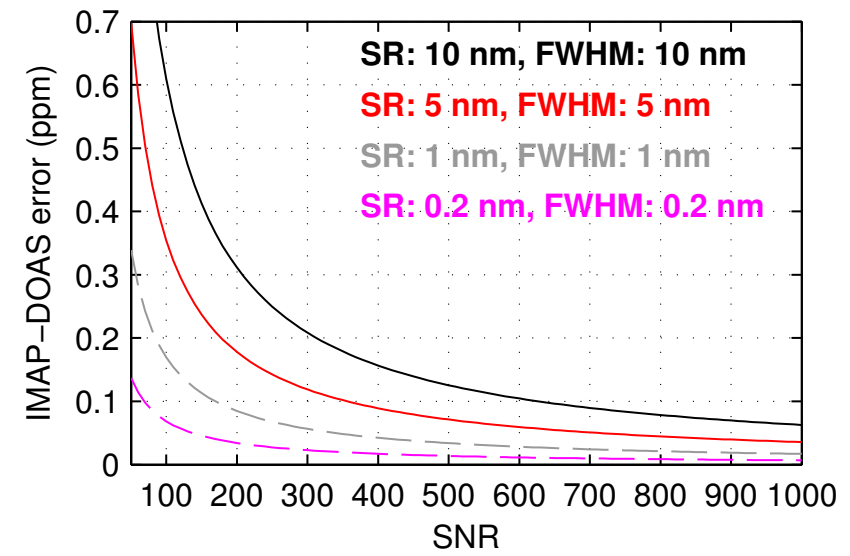

Fig. 6. Estimated IMAP-DOAS retrieval errors $\left(\mathrm{ppm} \mathrm{CH}_{4}\right.$ ) for four hypothetical sensors, each with the spectral resolution (SR) equal to the FWHM. Errors are relative to lowest atmospheric layer (height up to $1.04 \mathrm{~km}$ ) and decline with increased signal-to-noise ratio (SNR).

of hypothetical sensors with varying spectral resolution and FWHM across a range of SNR (Fig. 6). As expected, the IMAP-DOAS error decreases as SNR increases and as the spectral resolution and FWHM become finer. The black line $(10 \mathrm{~nm}$ spectral resolution and FWHM) approximates the AVIRIS sensor and the SNR for bands used in the IMAPDOAS retrieval was conservatively estimated between 100 and 200 using an AVIRIS instrument model for low albedo surfaces (Robert Green, personal communication, 2013). Using scene parameters similar to the COP flight $(8.9 \mathrm{~km}$ altitude, $11.4^{\circ}$ solar zenith), this corresponds to an error of between 0.31 to $0.61 \mathrm{ppm} \mathrm{CH}_{4}$ over the lowest atmospheric layer (up to $1.04 \mathrm{~km}$ ) shown in Fig. 2a. Given that about $10 \%$ of the total column is within the lowest layer, this error is considerable and roughly corresponds to an error of 30 to $60 \mathrm{ppb}$ in column-averaged $\mathrm{CH}_{4}$ over the total atmospheric column.

\section{Results for IMAP-DOAS}

\subsection{COP}

For the COP subset shown in Fig. 7a, measured radiance for the first band of the IMAP-DOAS retrieval window at $2278 \mathrm{~nm}$ had a minimum of 0.1158 , maximum of 6.436 (sensor saturation), and mean of 2.0516 microwatt $\mathrm{cm}^{-2} \mathrm{sr}^{-1} \mathrm{~nm}^{-1} \quad\left(\mathrm{uWcm}^{-2} \mathrm{sr}^{-1} \mathrm{~nm}^{-1}\right)$. Sensor saturation occurs only for a small portion of the scene where the full well of the detector is saturated for multiple channels in the SWIR. Sonar return contours of subsurface $\mathrm{CH}_{4}$ bubble plumes are overlain and correspond to known seep locations (Leifer et al., 2010). In Fig. 7b, the $\mathrm{CH}_{4}$ scaling factor is shown for the lowest atmospheric layer (height up to $1.04 \mathrm{~km}$ ) and a $\mathrm{CH}_{4}$ enhancement is clearly

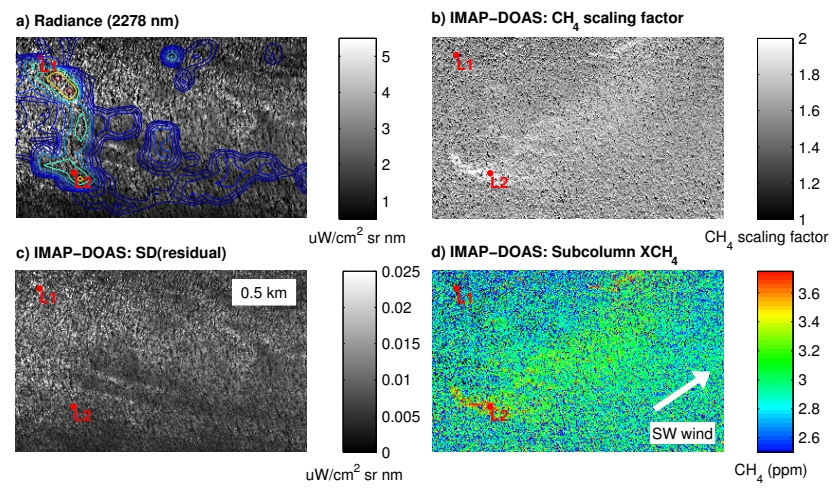

Fig. 7. (a) Measured radiance at $2278 \mathrm{~nm}$, showing strong variability in brightness. Sonar return contours (Leifer et al., 2010) are overlain and correspond to known seep locations. (b) For the same image subset, $\mathrm{CH}_{4}$ scaling factor for the lowest atmospheric layer (layer 10) indicates a $\mathrm{CH}_{4}$ plume consistent with the local wind direction. (c) The standard deviation of the residuals (measured minus modeled radiance) depends strongly on brightness (a). (d) Subcolumn $\mathrm{XCH}_{4}$ (ppm $\mathrm{CH}_{4}$ for the lowest layer), excluding bright pixels (greater than $5 \mathrm{uWcm}^{-2} \mathrm{sr}^{-1} \mathrm{~nm}^{-1}$ in the fitting window) associated with high standard deviation of the residuals. For two spectra (indicated by locations L1 and L2), measured and modeled radiance are provided in Fig. 8.

visible, consistent with emission from seep locations and the $2.3 \mathrm{~m} \mathrm{~s}^{-1}$ southwesterly wind measured at the nearby West Campus Station. The standard deviation of the residual (the difference between measured and modeled radiance) was also calculated to evaluate the ability of IMAP-DOAS to model radiance. This result is shown in Fig. 7c and has a similar visual appearance to Fig. 7a, indicating a strong albedo influence.

$\mathrm{CH}_{4}$ concentrations were calculated by multiplying the retrieved $\mathrm{CH}_{4}$ scaling factor by the VMR for the lowest atmospheric layer $\left(1.78 \mathrm{ppm} \mathrm{CH}_{4}\right)$. In Fig. $7 \mathrm{~d}$, ppm $\mathrm{CH}_{4}$ for the lowest layer is shown (subcolumn $\mathrm{XCH}_{4}$ ), excluding 740 bright pixels (greater than $5 \mathrm{uWcm}^{-2} \mathrm{sr}^{-1} \mathrm{~nm}^{-1}$ in the fitting window) associated with high standard deviation of the residuals. These results indicate enhancements in the lowest layer up to 2.5 times concentrations present in the reference atmosphere, equivalent to $4.46 \mathrm{ppm} \mathrm{CH}_{4}$ averaged across the distance from the ocean surface to $1.04 \mathrm{~km}$. However, there appears to be a positive bias in these results, given concentrations for locations upwind of the plume appear higher than the expected background concentration of $1.78 \mathrm{ppm}$. Therefore, the subcolumn $\mathrm{XCH}_{4}$ results appear overestimated. This observed bias will be further addressed in Sect. 11.

In Fig. 7, locations L1 and L2 correspond to the measured and modeled radiance plotted in Fig. 8. At location L1 (Fig. 8a), the measured radiance (black) is nearly horizontal for wavelengths between 2278 and $2328 \mathrm{~nm}$, indicating sensor saturation due to high sun glint. This causes considerable 


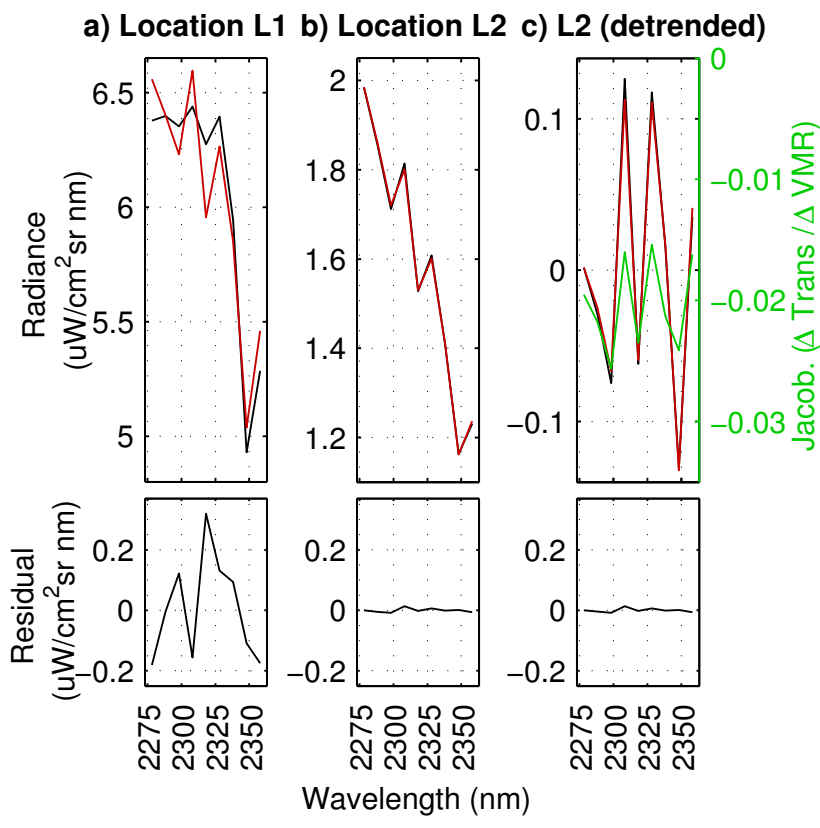

Fig. 8. (a) For location L1 (see Fig. 7), the measured radiance (black) indicates sensor saturation due to high sun glint between 2278 and $2328 \mathrm{~nm}$. This causes considerable disagreement with the modeled radiance (red), as indicated by the residual radiance shown in the bottom plot. (b) There is better agreement for location L2. (c) The radiance shown in (b) was detrended and the $\mathrm{CH}_{4}$ Jacobian for the lowest layer overlain (green) to indicate the location of $\mathrm{CH}_{4}$ absorptions at 2298, 2318, and $2348 \mathrm{~nm}$.

disagreement with the modeled radiance (red), as indicated by the residual radiance shown in the bottom plot; this pixel was excluded from the results shown in Fig. 7d. For Fig. 8b (location L2), the radiance is considerably lower and there is better agreement between measured and modeled radiance, resulting in a retrieved concentration of $2.18 \mathrm{ppm} \mathrm{CH}_{4}$ for this pixel. This radiance was detrended in Fig. 8c and the $\mathrm{CH}_{4}$ Jacobian for the lowest layer is overlain to indicate the location of $\mathrm{CH}_{4}$ absorptions at 2298, 2318, and $2348 \mathrm{~nm}$.

\subsection{Inglewood}

The Inglewood subset (Fig. 9a) is highly heterogeneous, with a maximum measured radiance of 0.8033 , minimum of 0.0192 , and mean of $0.2800 \mathrm{uWcm}^{-2} \mathrm{sr}^{-1} \mathrm{~nm}^{-1}$ at $2278 \mathrm{~nm}$. A road crosses the scene from north to south, separating the Inglewood Oil Field on the left from a residential neighborhood on the right. In this complex urban environment, the low order polynomial in the IMAP-DOAS algorithm is unable to account for some of the high-frequency spectral variability that interferes with $\mathrm{CH}_{4}$ absorptions. Therefore, the $\mathrm{CH}_{4}$ scaling factor results for the lowest atmospheric layer are heavily influenced by the land surface type (Fig. 9b). For example, the road appears clearly visible and high $\mathrm{CH}_{4}$ scaling factors occur for individual structures within the

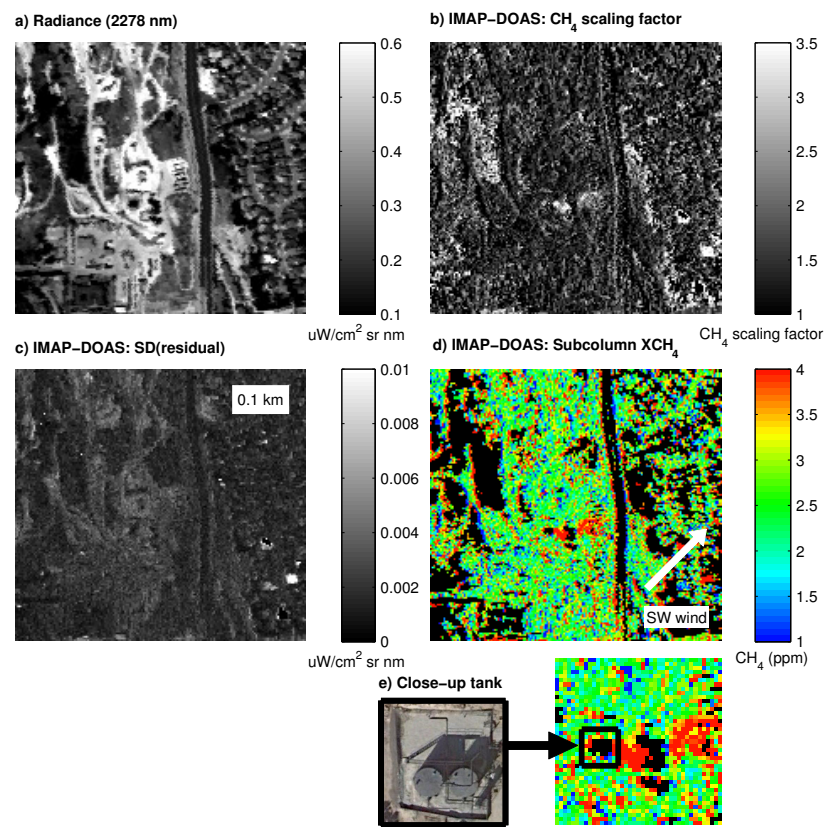

Fig. 9. (a) Radiance at $2278 \mathrm{~nm}$, showing a portion of the Inglewood Oil Field. (b) For the same image subset, $\mathrm{CH}_{4}$ scaling factor for the lowest atmospheric layer (layer 10) appears heavily influenced by land surface type. (c) Standard deviation of the residuals also appears influenced by land cover. (d) Subcolumn $\mathrm{XCH}_{4}$ (ppm $\mathrm{CH}_{4}$ for the lowest layer), excluding dark pixels (less than $0.1 \mathrm{uWcm}^{-2} \mathrm{sr}^{-1} \mathrm{~nm}^{-1}$ in the fitting window). (e) Close-up of hydrocarbon storage tanks upwind of observed plume (Google Earth, 2013).

neighborhood. Dark spectra also appear to have erroneously high $\mathrm{CH}_{4}$ scaling factors, including heavily vegetated areas in the northwest and southeast of the scene.

For the lowest atmospheric layer, subcolumn $\mathrm{XCH}_{4}$ results are shown in Fig. 9d, excluding dark pixels less than $0.1 \mathrm{uWcm}^{-2} \mathrm{sr}^{-1} \mathrm{~nm}^{-1}$ in the fitting window. While background concentrations are expected around $1.78 \mathrm{ppm} \mathrm{CH}_{4}$, observed background concentrations appear biased upward, between 2 and $3 \mathrm{ppm}$. Despite the noisy results, a feature of elevated $\mathrm{CH}_{4}$ is visible in the center of the image with maximum concentrations in excess of $5.5 \mathrm{ppm}$. This $\mathrm{CH}_{4}$ plume is consistent with a $2.2 \mathrm{~m} \mathrm{~s}^{-1}$ southwesterly wind measured nearby at the time of image acquisition (http://weatherunderground.com, 2012). Using higher resolution Google Earth imagery acquired one year after the AVIRIS flight, two hydrocarbon storage tanks were identified immediately upwind and are the probable emission source (Fig. 9e). 


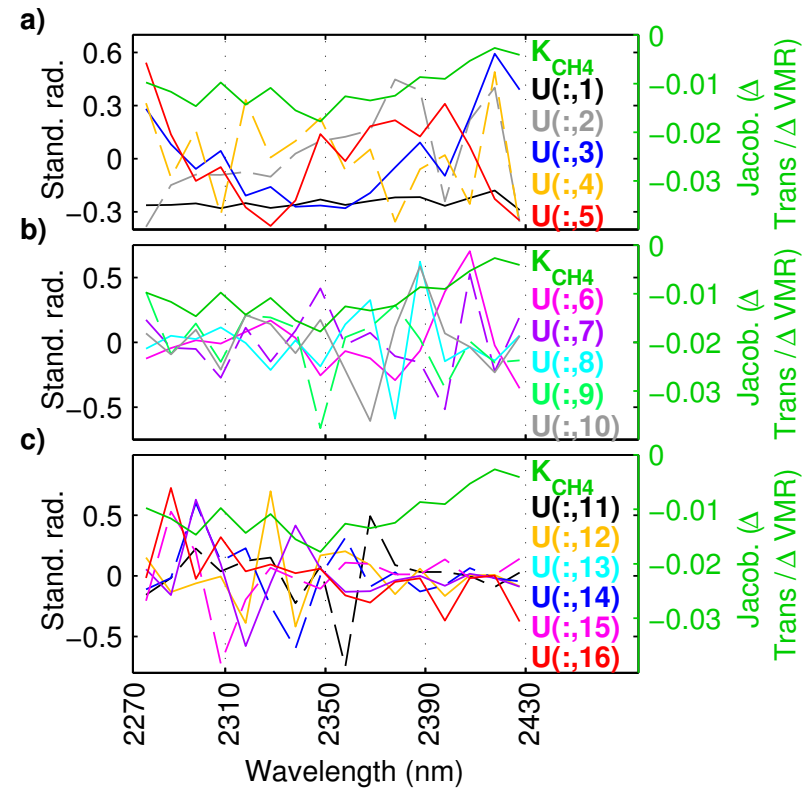

Fig. 10. (a) Singular vectors contained in $\mathbf{U}_{\text {econ }}$ for COP scene with $\mathrm{CH}_{4}$ Jacobian $\left(\mathrm{K}_{\mathrm{CH}_{4}}\right)$ plotted for reference.

\section{Results for SVD}

\subsection{COP}

While the IMAP-DOAS technique permitted $\mathrm{CH}_{4}$ retrievals for the more homogeneous marine location, high-frequency variation present in the terrestrial example interferes with $\mathrm{CH}_{4}$ absorptions and makes mapping more challenging. To permit retrievals for terrestrial locations, a hybrid approach using SVD and IMAP-DOAS was used to first account for high-frequency variation present in the scene and determine what variance of the standardized radiance resulted from changes in $\mathrm{CH}_{4}$.

In Fig. 10, all 16 columns of $\mathbf{U}_{\text {econ }}$ are shown in addition to the $\mathrm{CH}_{4}$ Jacobian $\left(\mathrm{K}_{\mathrm{CH}_{4}}\right)$. Following the iterative method described in Sect. 7, 4 of the total 16 columns of $\mathbf{U}_{\text {econ }}$ were used to generate $\mathbf{U}_{\text {select }}$ and account for over $99.99 \%$ of the variance. Next, $\mathbf{U}_{\text {select }}$ and $\mathbf{K}_{\mathrm{CH}_{4}}$ were concatenated to generate the $\mathbf{J}$ matrix, which is used for modeling radiance (see Eq. 9).

In Fig. 11b, the weights $\left(\mathrm{RCH}_{4}\right)$ associated with the column of $\mathbf{J}$ that corresponds to the $\mathrm{CH}_{4}$ Jacobian are shown (see Eq. 9). Within the scene, expected background values are 0 and the distinctive $\mathrm{CH}_{4}$ plume is similar to the IMAPDOAS results (Fig. 7b). In Fig. 12d, ppm $\mathrm{CH}_{4}$ relative to background is shown, excluding 323 pixels $(0.55 \%$ of total scene) associated with standard deviation of the residuals greater than 0.0075 (Fig. 11c; a unitless value given the SVD was performed on standardized radiance). $\mathrm{CH}_{4}$ concentrations exceed 3 ppm above background within the plume, gradually decrease downwind, and approach expected background concentrations.

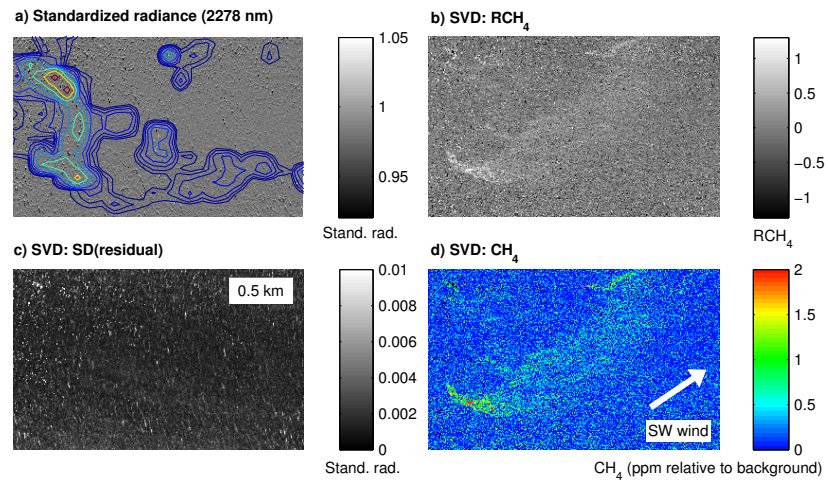

Fig. 11. (a) Standardized radiance used for calculating SVD at COP (showing only $2278 \mathrm{~nm}$ ). (b) For the same image subset, $\mathrm{RCH}_{4} \mathrm{re}$ sults clearly indicate $\mathrm{CH}_{4}$ plume. (c) The standard deviation of the residuals (measured minus modeled radiance). (d) $\mathrm{ppm}^{\mathrm{CH}} \mathrm{H}_{4}$ relative to background, excluding pixels with greater than 0.0075 standard deviation of the residual (a unitless value given the SVD was performed on standardized radiance).

\subsection{Inglewood}

Using the iterative method described in Sect. 7, 9 columns of $\mathbf{U}_{\text {econ }}$ were selected to generate $\mathbf{U}_{\text {select }}$ for the Inglewood scene. The $\mathrm{RCH}_{4}$ results (Fig. 12b) more clearly distinguish the $\mathrm{CH}_{4}$ plume compared to the IMAP-DOAS results (Fig. 9b); however, the SVD standard deviation of the residuals indicates higher errors for vegetated surfaces (Fig. 12c). Excluding pixels with greater than 0.0075 standard deviation of the residual, retrieved concentrations relative to background are shown in Fig. 12d. Expected background concentrations are observed throughout much of the scene and $\mathrm{CH}_{4}$ concentrations are highest for the western portion of the plume (in excess of $4 \mathrm{ppm}$ above background).

In Fig. 12, locations L3 and L4 correspond to the measured and modeled radiance plotted in Fig. 13. At location L3 (Fig. 13a), there is considerable disagreement between the measured (black) and modeled radiance (red), as indicated by the residual. L3 is located in a vegetated region and because the standard deviation of the residual exceeds 0.0075 , this pixel was excluded from the results shown in Fig. 12d. In contrast, there is good agreement for L4, which is made up of bare soil with an estimated concentration of $0.38 \mathrm{ppm}$ $\mathrm{CH}_{4}$ above background (Fig. 13b).

As described in Sect. 9.2, high standard deviation of the residuals were observed for dark pixels in IMAP-DOAS results for the Inglewood scene (Fig. 9c). In Fig. 9d, dark pixels less than $0.1 \mathrm{uWcm}^{-2} \mathrm{sr}^{-1} \mathrm{~nm}^{-1}$ in the fitting window were excluded from IMAP-DOAS results, which included vegetated surfaces. For the hybrid approach using SVD and IMAP-DOAS, pixels with greater than 0.0075 standard deviation of the residual were excluded from the results shown in Fig. 12d, also corresponding to vegetation within the scene. The average radiance at $2278 \mathrm{~nm}$ for 


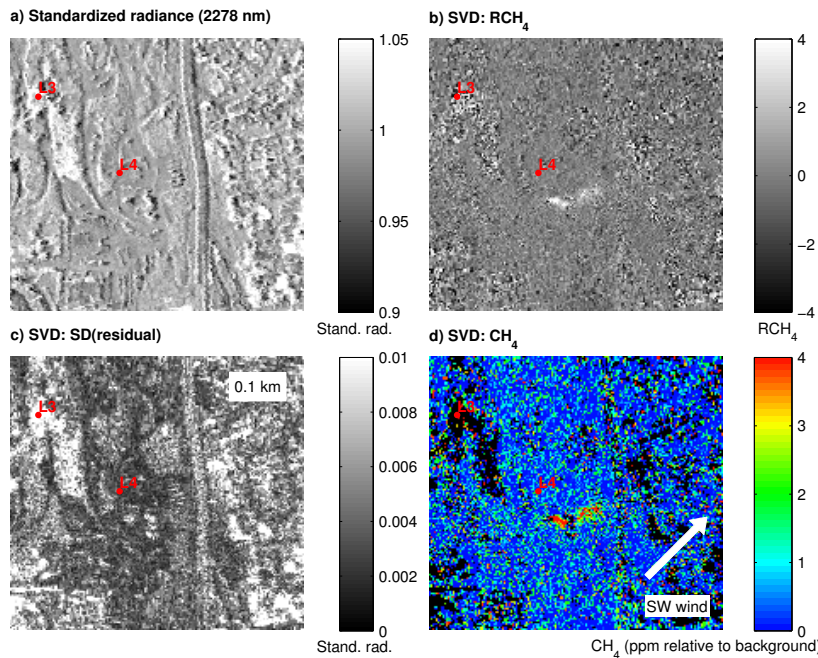

Fig. 12. (a) Standardized radiance used for calculating SVD for Inglewood subset (showing only $2278 \mathrm{~nm}$ ). (b) For the same image subset, $\mathrm{RCH}_{4}$ results indicate $\mathrm{CH}_{4}$ plume at the center of the scene. (c) The standard deviation of the residuals (measured minus modeled radiance). (d) $\mathrm{ppm} \mathrm{CH}_{4}$ relative to background, excluding pixels with greater than 0.0075 standard deviation of the residual (a unitless value given the SVD was performed on standardized radiance). For two spectra (indicated by locations L3 and L4), measured and modeled radiance are provided in Fig. 13.

those pixels with greater than 0.0075 standard deviation of the residual for the hybrid approach (Fig. 12d, black pixels) was only $0.1368 \mathrm{uWcm}^{-2} \mathrm{sr}^{-1} \mathrm{~nm}^{-1}$, compared to the $0.3129 \mathrm{uWcm}^{-2} \mathrm{sr}^{-1} \mathrm{~nm}^{-1}$ average for the remaining pixels in the scene. Dark pixels and their corresponding low SNR cause lower single measure precision and are thus problematic for both the IMAP-DOAS and the hybrid approach.

\section{Discussion}

\subsection{Comparison of retrieval results}

The IMAP-DOAS and hybrid SVD approach were capable of quantifying $\mathrm{CH}_{4}$ concentrations from plumes over marine and terrestrial environments. For both techniques, agreement between measured and modeled radiance was poorest at albedo extremes, for example saturated pixels at COP and dark, vegetated surfaces at Inglewood. SVD results indicate near surface enhancements relative to background; absorptions resulting from background $\mathrm{CH}_{4}$ concentrations in the scene are contained in $\mathbf{U}_{\text {select }}$ and the retrieval used the $\mathrm{CH}_{4}$ Jacobian from the lowest layer of the atmospheric model. Similarly, the IMAP-DOAS retrieval also provides ppm $\mathrm{CH}_{4}$ enhancements averaged over the lowest atmospheric layer (up to $1.04 \mathrm{~km}$ ).

For the IMAP-DOAS results from COP and Inglewood, an average background ppm $\mathrm{CH}_{4}$ concentration was calculated

\section{a) Location L3}

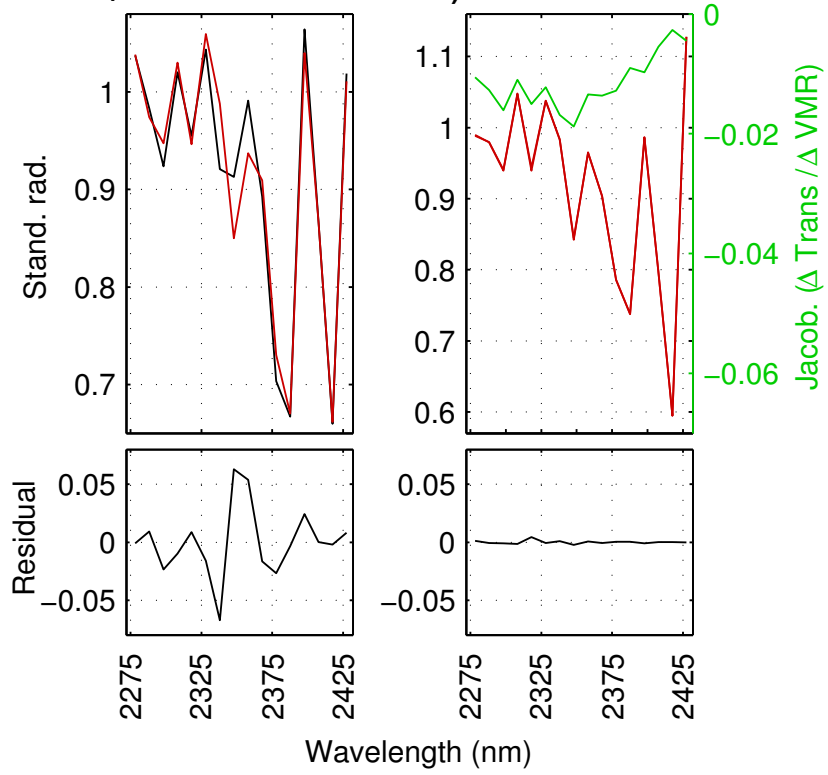

Fig. 13. (a) The modeled (red) and measured standardized radiance (black) for location L3, which corresponds to a dark spectrum with an average radiance of $0.0376 \mathrm{uWcm}^{-2} \mathrm{sr}^{-1} \mathrm{~nm}^{-1}$. L3 is located in a distinct region with high values for the standard deviation of the residuals (see Fig. 12c) and was excluded from the results shown in Fig. 12d. (b) For location L4, there is better agreement between modeled and measured radiance (average $0.5187 \mathrm{uWcm}^{-2} \mathrm{sr}^{-1} \mathrm{~nm}^{-1}$ ). The $\mathrm{CH}_{4}$ Jacobian for the lowest layer is overlain (green) to indicate the location of $\mathrm{CH}_{4}$ absorptions.

for the portion of the scene selected to represent homogeneous land cover (see Sect. 7). To account for the observed positive bias in subcolumn $\mathrm{XCH}_{4}$ (see Sect. 9), this average concentration was subtracted from subcolumn $\mathrm{XCH}_{4}$, resulting in ppm $\mathrm{CH}_{4}$ relative to background. However, different portions of each scene were excluded from IMAP-DOAS and SVD results due to observed biases. For example, pixels were excluded from IMAP-DOAS results at Inglewood using an albedo threshold (Fig. 9d), while a standard deviation of the residual threshold was applied to SVD results (Fig. 12d). To permit comparison between results, only those pixels not excluded from either the IMAP-DOAS or SVD results are shown in Figs. 14 and 15.

These results were also compared with an independent technique, the cluster-tuned matched filter (CTMF) that was applied to both scenes (Figs. 14c and 15c). The CTMF is trained with a gas transmittance spectrum as a target to calculate CTMF scores for each image pixel where scores greater than one indicate significant evidence of the gas signature (Funk et al., 2001). Because the CTMF uses the inverse of the scene's covariance structure to remove large-scale noise to isolate the gas signal, it is best suited for detecting concentrated sources rather than background concentrations. A detailed description of the CTMF algorithm including results 

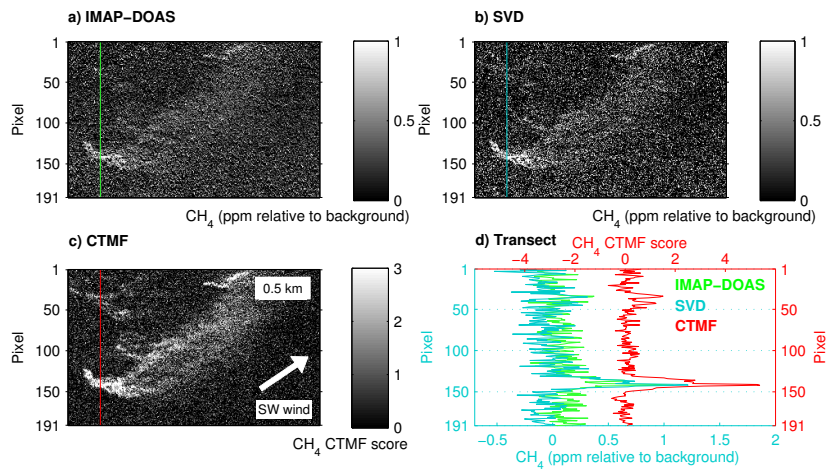

Fig. 14. For the same COP subset, there is good agreement between results obtained using three techniques: (a) IMAP-DOAS, (b) SVD, and (c) cluster-tuned matched filter (CTMF). (d) The location of a vertical transect is shown for the IMAP-DOAS (green line), SVD (cyan), and CTFM results (red); values along the transect are shown for IMAP-DOAS (green), SVD (cyan), and CTMF (red). At each point along the transect, an average value was calculated for 21 pixels centered on the transect in the horizontal direction. IMAP-DOAS and SVD transects share the cyan figure axes, while the CTMF transect was offset for clarity and corresponds to the red figure axes.

from both the COP and Inglewood image subsets is available in Thorpe et al. (2013). The CTMF does not provide an estimate of gas concentrations; rather, it provides an image of gas anomalies that can be evaluated for consistency with probable emissions sources and local wind direction. In contrast, IMAP-DOAS and the hybrid SVD approach provide $\mathrm{CH}_{4}$ concentrations as well as uncertainty estimates.

At COP, there is good spatial agreement between the observed plumes obtained with the IMAP-DOAS (Fig. 14a), hybrid SVD (Fig. 14b), and CTMF (Fig. 14c) approaches (Thorpe et al., 2013). IMAP-DOAS $\mathrm{CH}_{4}$ concentrations are generally higher (mean 0.12 , standard deviation $0.43 \mathrm{ppm}$ relative to background) than the SVD results (mean -0.01 , standard deviation $0.63 \mathrm{ppm}$ relative to background). The location of an identical transect is shown for the IMAP-DOAS (Fig. 14a, green line), SVD (Fig. 14b, cyan), and CTMF results (Fig. 14c, red). At each point along the transect, an average value was calculated for 21 pixels centered on the transect in the horizontal direction. The average values along the transect are plotted in Fig. 14d and indicate concentrations for IMAP-DOAS (green), which are generally higher than for the SVD approach (cyan) with both transects sharing the cyan figure axes. Where the transect intersects the plume, there is good agreement in the pronounced peak in values from the three techniques, including CTMF results (red) that were offset for clarity and correspond to the red figure axes. While the CTMF technique appears better suited for detecting diffuse portions of the plume (Fig. 14c), it does not provide $\mathrm{CH}_{4}$ concentrations.
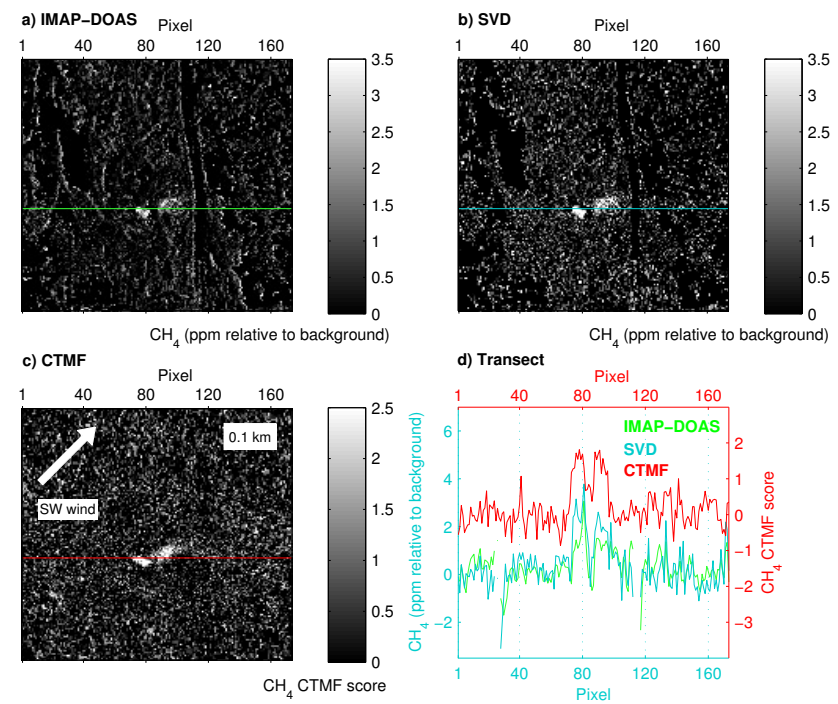

Fig. 15. For the same Inglewood subset, there is good agreement between results obtained using three techniques: (a) IMAP-DOAS, (b) SVD, and (c) cluster-tuned matched filter (CTMF). (d) The location of a horizontal transect is shown for the IMAP-DOAS (green line), SVD (cyan), and CTMF results (red); values along the transect are shown for IMAP-DOAS (green), SVD (cyan), and CTMF (red) approach. At each point along the transect, an average value was calculated for 9 pixels centered on the transect in the vertical direction. IMAP-DOAS and SVD transects share the cyan figure axes, while the CTMF transect was offset for clarity and corresponds to the red figure axes.

Using the hybrid SVD approach, the maximum observed concentration within the scene was $2.85 \mathrm{ppm} \mathrm{CH}_{4}$ above background, located at a region of subsurface $\mathrm{CH}_{4}$ bubble plumes, as shown by the sonar return contours (Fig. 11a). Averaged over the lowest atmospheric layer (a distance of $1.04 \mathrm{~km}$ ), this maximum concentration will increase when scaled for a smaller atmospheric column. For example, concentrations increase to $590 \mathrm{ppm} \mathrm{CH}_{4}$ above background if all enhancements are within a $5 \mathrm{~m}$ atmospheric column. Near surface concentrations are likely much higher; Leifer et al. (2006) measured up to $2 \times 10^{4} \mathrm{ppm} \mathrm{CH}_{4}$ at $5 \mathrm{~m}$ height using a flame ion detector.

For Inglewood, the $\mathrm{CH}_{4}$ plume is clearly visible in IMAPDOAS (Fig. 15a), hybrid SVD (Fig. 15b), and CTMF (Fig. 15c) results (Thorpe et al., 2013). $\mathrm{CH}_{4}$ concentrations for IMAP-DOAS are generally higher (mean 0.13 and standard deviation $1.03 \mathrm{ppm}$ relative to background) than the hybrid SVD results (mean -0.04 and standard deviation $1.60 \mathrm{ppm}$ relative to background). Overall there is good spatial agreement for the observed $\mathrm{CH}_{4}$ plume obtained using these three distinct techniques.

Similar to the COP comparison, the location of an identical transect is shown for the IMAP-DOAS, SVD, and CTMF results. An average was calculated at each point along the transect (for 9 pixels centered on the transect in the vertical 
direction) and plotted in Fig. 15d, indicating two locations with enhanced $\mathrm{CH}_{4}$ between the 70th and 100th pixels. For this portion of the transect, there is considerable disagreement between the IMAP-DOAS (Fig. 15d, green line) and SVD concentrations (blue). This discrepancy can be partly attributed to the influence of the choice of the number of columns of $\mathbf{U}_{\text {econ }}$ used to generate $\mathbf{U}_{\text {select }}$ (see Sect. 7). For the transect shown in Fig. 15d, 9 columns of $\mathbf{U}_{\text {econ }}$ were used, resulting in a mean concentration along the transect of $0.4141 \mathrm{ppm} \mathrm{CH}_{4}$ relative to background. Selecting 10 columns of $\mathbf{U}_{\text {econ }}$ decreased the mean concentration along the transect to $0.3664 \mathrm{ppm}$ relative to background with a standard deviation of the difference between transects obtained using 9 and 10 columns equal to $0.2959 \mathrm{ppm}$. In contrast, using 8 columns of $\mathbf{U}_{\text {econ }}$ results in a mean concentration of $0.4144 \mathrm{ppm}$ relative to background, and the standard deviation of the difference between transects obtained using 9 and 8 columns is reduced to $0.1508 \mathrm{ppm}$ relative to background. This indicates that retrieved $\mathrm{CH}_{4}$ concentrations obtained using the SVD approach is influenced by the choice of $\mathbf{U}_{\text {select }}$ because higher-order singular vectors can start correlating with the computed $\mathrm{CH}_{4}$ Jacobian.

For the SVD approach at Inglewood using 9 columns of $\mathbf{U}_{\text {econ }}$, the maximum within the $\mathrm{CH}_{4}$ plume was $8.45 \mathrm{ppm}$ above background with concentrations decreasing downwind of the hydrocarbon storage tanks (Fig. 12d). Such enhancements are feasible given tanks represent large emission sources; natural gas storage tanks can emit between 4.3 and $42.0 \times 10^{-4} \mathrm{Gg} \mathrm{CH}_{4}$ per $\left(10^{6}\right) \mathrm{m}^{3}$ gas withdrawals per year (IPCC, 2000) and tank venting represented approximately $14.4 \%\left(212 \mathrm{Gg} \mathrm{CH}_{4}\right)$ of the total US $\mathrm{CH}_{4}$ emissions from petroleum systems in 2009 (EPA, 2011).

\subsection{Potential for AVIRISng and future sensors}

While $\mathrm{CH}_{4}$ retrievals are promising using AVIRIS, the next generation sensor (AVIRISng) will have a $5 \mathrm{~nm}$ spectral resolution and FWHM, which should significantly improve $\mathrm{CH}_{4}$ sensitivity. An IMAP-DOAS retrieval error between 0.31 to $0.61 \mathrm{ppm} \mathrm{CH}_{4}$ over the lowest atmospheric layer (height up to $1.04 \mathrm{~km}$ ) is expected for an AVIRIS scene acquired at $8.9 \mathrm{~km}$ altitude, $11.4^{\circ}$ solar zenith, and with a SNR conservatively set between 100 and 200 (Fig. 6, black line). This corresponds to about a 32 to $63 \mathrm{ppm}$ retrieval error for a $10 \mathrm{~m}$ thick plume or 322 to $634 \mathrm{ppm}$ for a $1 \mathrm{~m}$ thick plume. For a similar AVIRISng scene, the IMAP-DOAS retrieval error would be reduced to between 0.18 to $0.35 \mathrm{ppm}$ over the lowest atmospheric layer for the same range of SNR (Fig. 6, red line); however, retrieval errors remain significant. In addition, SNR for AVIRISng should be considerably improved, further reducing retrieval errors.

To further assess this increased sensitivity, $\mathrm{CH}_{4}$ Jacobians were calculated for AVIRISng and AVIRIS for a $5 \% \mathrm{CH}_{4}$ enhancement over the lowest atmospheric layer. In Fig. 16a, the AVIRIS $\mathrm{CH}_{4}$ Jacobian (black line) has

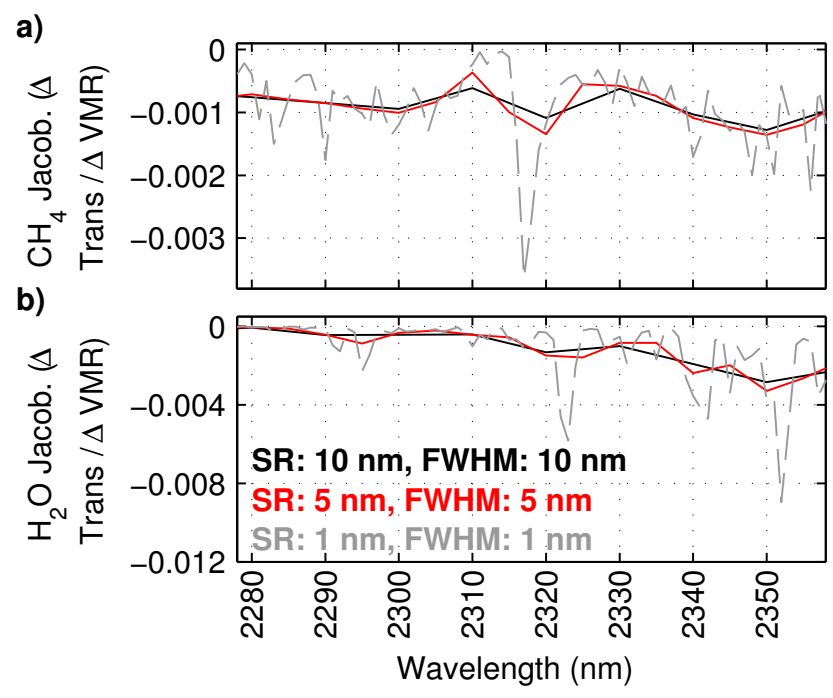

Fig. 16. (a) For the lowest layer of the atmopsheric model (height up to $1.04 \mathrm{~km}$ ), the $\mathrm{CH}_{4}$ Jacobian calculated for AVIRISng (red) indicates improved sensitivity compared to the $\mathrm{CH}_{4}$ Jacobian for AVIRIS (black). Even greater sensitivity can be achieved using a finer spectral resolution (SR) and FWHM (dashed grey). (b) $\mathrm{H}_{2} \mathrm{O}$ Jacobians calculated for the same three sensors.

a $-4.7 \times 10^{-4} \Delta \mathrm{uWcm}^{-2} \mathrm{sr}^{-1} \mathrm{~nm}^{-1} / \Delta \mathrm{VMR}$ amplitude between a peak at $2310 \mathrm{~nm}$ and the $\mathrm{CH}_{4}$ absorption at $2320 \mathrm{~nm}$. For AVIRISng (red line) this amplitude is $-9.8 \times$ $10^{-4} \Delta \mathrm{uWcm}^{-2} \mathrm{sr}^{-1} \mathrm{~nm}^{-1} / \Delta \mathrm{VMR}$, roughly representing a doubling of $\mathrm{CH}_{4}$ sensitivity compared with AVIRIS. However, additional improvements should result from a greater number of detector pixels and the improved SNR of AVIRISng. Sensors with a finer spectral resolution and FWHM offer the potential for even greater sensitivity, as shown by the grey line in Fig. 16a for a spectral resolution and FWHM of $1 \mathrm{~nm}$ and reduced IMAP-DOAS retrieval errors indicated by the grey dashed line in Fig. 6 .

\section{Conclusions}

In this study, two retrieval techniques were used to measure $\mathrm{CH}_{4}$ enhancements for concentrated plumes over marine and terrestrial locations in AVIRIS data. The IMAPDOAS algorithm performed well for the homogenous ocean scene containing the COP seeps, and retrieval errors are esti-

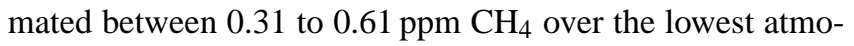
spheric layer (height up to $1.04 \mathrm{~km}$ ). For the Inglewood subset, IMAP-DOAS results became heavily influenced by the underlying land cover, while the hybrid SVD approach was particularly effective given that it could better account for spectrally variable surface reflectance. Using the hybrid SVD approach for the COP and Inglewood plumes, maximum near surface concentrations were 2.85 and $8.45 \mathrm{ppm} \mathrm{CH}_{4}$ above background, respectively. An additional benefit of the hybrid 
SVD approach is that it requires less than half the computational time than that of the IMAP-DOAS retrieval.

Given a $5 \mathrm{~nm}$ spectral resolution and $\mathrm{FWHM}, \mathrm{CH}_{4}$ sensitivity should be more than doubled for AVIRISng. This might permit $\mathrm{CH}_{4}$ retrievals for weaker absorption features centered at $1650 \mathrm{~nm}$, as well as $\mathrm{CO}_{2}$ retrievals for absorptions at 1572,1602 , and $2058 \mathrm{~nm}$. However, both the AVIRIS and AVIRISng sensors were not designed for detecting gas plumes, and sensitivity could likely be dramatically improved using a spectrometer designed exclusively for mapping gas plumes. For example, an imaging spectrometer with $0.05 \mathrm{~nm}$ spectral resolution and $0.15 \mathrm{~nm}$ FWHM would have an IMAP-DOAS error around 18 times smaller than AVIRIS.

While non-imaging spectrometers such as MAMAP have increased $\mathrm{CH}_{4}$ sensitivity compared to AVIRIS and AVIRISng, they are currently limited to flying transects across local gas plumes due to a small field of view. In contrast, airborne imaging spectrometers combine large image footprints and fine spatial resolution necessary to map local $\mathrm{CH}_{4}$ plumes in their entirety; however, they have considerably higher expected errors for retrieved $\mathrm{CH}_{4}$ concentrations.

In this study, the observed COP plume extended more than $1 \mathrm{~km}$; however, the Inglewood plume was much smaller, extending only $0.1 \mathrm{~km}$ downwind. Such plumes with a small spatial extent are of increasing concern, including industrial point source emissions, leaking gas pipelines (Murdock et al., 2008), and fugitive $\mathrm{CH}_{4}$ emissions (Howarth et al., 2011). Imaging spectrometers permit direct attribution of emissions to individual point sources, which is particularly useful given the large uncertainties associated with anthropogenic emissions, including fugitive $\mathrm{CH}_{4}$ emissions from the oil and gas industry (Petron et al., 2012; EPA, 2013; Allen et al., 2013), and the projected increase in these types of emissions (EPA, 2006). Therefore, AVIRIS-like sensors offer the potential to better constrain emissions on local and regional scales (NRC, 2010), improve greenhouse gas budgets and partitioning between natural and anthropogenic sources, as well as complement data provided at coarser spatial resolutions.

Acknowledgements. NCEP Reanalysis data provided by the NOAA/OAR/ESRL PSD, Boulder, Colorado, USA, from their web site at http://www.esrl.noaa.gov/psd/. The authors would like to thank Debra Wunch for aiding in generating NCEP atmospheric profiles and for the continued support of Robert Green and the rest of the AVIRIS/AVIRISng team at the Jet Propulsion Laboratory. In addition, we thank Joseph McFadden for his insightful comments. This work was supported by NASA Headquarters under the NASA Earth and Space Science Fellowship Program grant NNX13AM95H. This work was undertaken in part at the Jet Propulsion Laboratory, California Institute of Technology, under contract with NASA as well as at the University of California, Santa Barbara.

Edited by: J. Notholt

\section{References}

Allen, D. T., Torres, V. M., Thomas, J., Sullivan, D. W., Harrison, M., Hendler, A., Herndon, S. C., Kolb, C. E., Fraser, A., Hill, D., Lamb, B. K., Miskimins, J., Sawyer, R. F., and Seinfeld, J. H.: Measurements of methane emissions at natural gas production sites in the United States, P. Natl. Acad. Sci., 110, 17768-17773, doi:10.1073/pnas.1304880110, 2013.

ARCTAS: Arctic Research of the Composition of the Troposphere from Aircraft and Satellites (ARCTAS), National Aeronautics and Space Administration (NASA), 2010.

Berk, A., Bernstein, L. S., and Robertson, D. C.: MODTRAN: A moderate resolution model for LOWTRAN7, AFGL-TR-890122, MA: Hanscom Air Force Base, 1989.

Bovensmann, H., Doicu, A., Stammes, P., Van Roozendael, M., von Savigny, C., Penning de Vries, M., Beirle, S., Wagner, T., Chance, K., Buchwitz, M., Kokhanovsky, A., Richter, A., Rozanov, A. V., and Rozanov, V. V.: From Radiation Fields to Atmospheric Concentrations - Retrieval of Geophysical Parameters, in: SCIAMACHY - Exploring the Changing Earth's Atmopshere, edited by: Gottwald, M. and Bovensmann, H., Springer, Dordrecht, 2011.

Bradley, E. S., Leifer, I., Roberts, D. A., Dennison, P. E., and Washburn, L.: Detection of marine methane emissions with AVIRIS band ratios, Geophys. Res. Lett., 38, L10702, doi:10.1029/2011GL046729, 2011.

Buchwitz, M., Rozanov, V. V., and Burrows, J. P.: A near-infrared optimized DOAS method for the fast global retrieval of atmospheric $\mathrm{CH}_{4}, \mathrm{CO}, \mathrm{CO}_{2}, \mathrm{H}_{2} \mathrm{O}$, and $\mathrm{N}_{2} \mathrm{O}$ total column amounts from SCIAMACHY Envisat-1 nadir radiances, J. Geophys. Res.Atmos., 105, 15231-15245, 2000.

Buchwitz, M. and Burrows, J. P.: Retrieval of $\mathrm{CH}_{4}, \mathrm{CO}$, and $\mathrm{CO}_{2}$ total column amounts from SCIAMACHY near-infrared nadir spectra: retrieval algorithm and first results, Proc. SPIE, 5235, 375-388, doi:10.1117/12.514219, 2003.

Buchwitz, M., de Beek, R., Noël, S., Burrows, J. P., Bovensmann, H., Bremer, H., Bergamaschi, P., Körner, S., and Heimann, M.: Carbon monoxide, methane and carbon dioxide columns retrieved from SCIAMACHY by WFM-DOAS: year 2003 initial data set, Atmos. Chem. Phys., 5, 3313-3329, doi:10.5194/acp-53313-2005, 2005.

Dennison, P. E., Thorpe, A. K., Pardyjak, E. R., Roberts, D. A., Qi, Y., Green, R. O., Bradley, E. S., and Funk, C. C.: High spatial resolution mapping of elevated atmospheric carbon dioxide using airborne imaging spectroscopy: radiative transfer modeling and power plant plume detection, Remote Sens. Environ., in press, 2013.

DOGGR: Online Production and Injection Query, State of California Department of Conservation, Division of Oil, Gas \& Geothermal Resources (DOGGR), available at: http://opi.consrv.ca.gov/ opi/opi.dll (1 February 2014), 2010.

Dufour, E. and Breon, F. M.: Spaceborne estimate of atmospheric $\mathrm{CO}_{2}$ column by use of the differential absorption method: error analysis, Appl. Optics, 42, 3595-3609, doi:10.1364/AO.42.003595, 2003.

EPA: Global Anthropogenic Non- $\mathrm{CO}_{2}$ Greenhouse Gas Emissions: 1990-2020, United States Environmental Protection Agency (EPA), Washington, D.C., 274, 2006. 
EPA: Inventory of US Greenhouse Gas Emissions and Sinks: 19902009, United States Environmental Protection Agency (EPA), Washington, D.C., 459 pp., 2011.

EPA: Inventory of US Greenhouse Gas Emissions and Sinks: 19902011, United States Environmental Protection Agency (EPA), Washington, D.C., 505 pp., 2013.

Etheridge, D. M., Steele, L. P., Francey, R. J., and Langenfelds, R. L.: Atmospheric methane between 1000 AD and present: Evidence of anthropogenic emissions and climatic variability, J. Geophys. Res.-Atmos., 103, 15979-15993, doi:10.1029/98jd00923, 1998.

Etiope, G., Feyzullayev, A., and Baciu, C. L.: Terrestrial methane seeps and mud volcanoes: A global perspective of gas origin, Mar. Petrol. Geol., 26, 333-344, doi:10.1016/j.marpetgeo.2008.03.001, 2009.

Frankenberg, C., Meirink, J. F., van Weele, M., Platt, U., and Wagner, T.: Assessing methane emissions from global space-borne observations, Science, 308, 1010-1014, doi:10.1126/science.1106644, 2005a.

Frankenberg, C., Platt, U., and Wagner, T.: Retrieval of CO from SCIAMACHY onboard ENVISAT: detection of strongly polluted areas and seasonal patterns in global CO abundances, Atmos. Chem. Phys., 5, 1639-1644, doi:10.5194/acp-5-1639-2005, 2005b.

Frankenberg, C., Platt, U., and Wagner, T.: Iterative maximum a posteriori (IMAP)-DOAS for retrieval of strongly absorbing trace gases: Model studies for $\mathrm{CH} 4$ and $\mathrm{CO}_{2}$ retrieval from near infrared spectra of SCIAMACHY onboard ENVISAT, Atmos. Chem. Phys., 5, 9-22, doi:10.5194/acp-5-9-2005, 2005c.

Frankenberg, C., Aben, I., Bergamaschi, P., Dlugokencky, E. J., van Hees, R., Houweling, S., van der Meer, P., Snel, R., and Tol, P.: Global column-averaged methane mixing ratios from 2003 to 2009 as derived from SCIAMACHY: Trends and variability, J. Geophys. Res.-Atmos., 116, D04302, doi:10.1029/2010jd014849, 2011.

Funk, C. C., Theiler, J., Roberts, D. A., and Borel, C. C.: Clustering to improve matched filter detection of weak gas plumes in hyperspectral thermal imagery, IEEE T. Geosci. Remote, 39, 1410-1420, 2001.

Gerilowski, K., Tretner, A., Krings, T., Buchwitz, M., Bertagnolio, P. P., Belemezov, F., Erzinger, J., Burrows, J. P., and Bovensmann, H.: MAMAP - a new spectrometer system for columnaveraged methane and carbon dioxide observations from aircraft: instrument description and performance analysis, Atmos. Meas. Tech., 4, 215-243, doi:10.5194/amt-4-215-2011, 2011.

Green, R. O., Eastwood, M. L., Sarture, C. M., Chrien, T. G., Aronsson, M., Chippendale, B. J., Faust, J. A., Pavri, B. E., Chovit, C. J., Solis, M. S., Olah, M. R., and Williams, O.: Imaging spectroscopy and the Airborne Visible Infrared Imaging Spectrometer (AVIRIS), Remote Sens. Environ., 65, 227-248, 1998.

Guanter, L., Frankenberg, C., Dudhia, A., Lewis, P. E., GomezDans, J., Kuze, A., Suto, H., and Grainger, R. G.: Retrieval and global assessment of terrestrial chlorophyll fluorescence from GOSAT space measurements, Remote Sens. Environ., 121, 236251, doi:10.1016/j.rse.2012.02.006, 2012.

Hornafius, J. S., Quigley, D., and Luyendyk, B. P.: The world's most spectacular marine hydrocarbon seeps (Coal Oil Point, Santa Barbara Channel, California): Quantification of emissions, J. Geophys. Res.-Oceans, 104, 20703-20711, 1999.
Houweling, S., Dentener, F., and Lelieveld, J.: Simulation of preindustrial atmospheric methane to constrain the global source strength of natural wetlands, J. Geophys. Res.-Atmos., 105, 17243-17255, 2000.

Howarth, R. W., Santoro, R., and Ingraffea, A.: Methane and the greenhouse-gas footprint of natural gas from shale formations, Climatic Change, 106, 679-690, doi:10.1007/s10584-011-0061$5,2011$.

Hurley, J., Dudhia, A., and Grainger, R. G.: Cloud detection for MIPAS using singular vector decomposition, Atmos. Meas. Tech., 2, 533-547, doi:10.5194/amt-2-533-2009, 2009.

IPCC: Good Practice Guidance and Uncertainty Management in National Greenhouse Gas Inventories, Cambridge Univ. Press, New York, 2000.

IPCC: Climate Change 2007: The Physical Science Basis. Contribution of Working Group I to the Fourth Assessment Report of the Intergovernmental Panel on Climate Change, Intergovernmental Panel on Climate Change (IPCC), Cambridge Univ. Press, New York, 881, 2007.

Kalnay, E., Kanamitsu, M., Kistler, R., Collins, W., Deaven, D., Gandin, L., Iredell, M., Saha, S., White, G., Woollen, J., Zhu, Y., Chelliah, M., Ebisuzaki, W., Higgins, W., Janowiak, J., Mo, K. C., Ropelewski, C., Wang, J., Leetmaa, A., Reynolds, R., Jenne, R., and Joseph, D.: The NCEP/NCAR 40-year reanalysis project, B. Am. Meteorol. Soc., 77, 437-471, doi:10.1175/15200477(1996)077<0437:Tnyrp>2.0.Co;2, 1996.

Kneizys, F. X., Abreu, L. W., Anderson, G. P., Chetwynd, J. H., Shettle, E. P., Robertson, D. C., Acharya, P., Rothman, L., Selby, J. E. A., Gallery, W. O., and Clough, S. A.: The MODTRAN 2/3 report and LOWTRAN 7 model, Tech. rep., Phillips Laboratory, Geophysics Directorate, Hanscom AFB, 1996.

Krings, T., Gerilowski, K., Buchwitz, M., Reuter, M., Tretner, A., Erzinger, J., Heinze, D., Pflüger, U., Burrows, J. P., and Bovensmann, H.: MAMAP - a new spectrometer system for columnaveraged methane and carbon dioxide observations from aircraft: retrieval algorithm and first inversions for point source emission rates, Atmos. Meas. Tech., 4, 1735-1758, doi:10.5194/amt-41735-2011, 2011.

Krings, T., Gerilowski, K., Buchwitz, M., Hartmann, J., Sachs, T., Erzinger, J., Burrows, J. P., and Bovensmann, H.: Quantification of methane emission rates from coal mine ventilation shafts using airborne remote sensing data, Atmos. Meas. Tech., 6, 151-166, doi:10.5194/amt-6-151-2013, 2013.

Kvenvolden, K. A.: Methane Hydrate - a Major Reservoir of Carbon in the Shallow Geosphere, Chem. Geol., 71, 41-51, 1988.

Kvenvolden, K. A. and Rogers, B. W.: Gaia's breath global methane exhalations, Mar. Petrol. Geol., 22, 579-590, doi:10.1016/j.marpetgeo.2004.08.004, 2005.

Leifer, I., Luyendyk, B. P., Boles, J., and Clark, J. F.: Natural marine seepage blowout: Contribution to atmospheric methane, Global Biogeochem. Cy., 20, GB3008, doi:10.1029/2005gb002668, 2006.

Leifer, I., Kamerling, M. J., Luyendyk, B. P., and Wilson, D. S.: Geologic control of natural marine hydrocarbon seep emissions, Coal Oil Point seep field, California, Geo-Mar Lett., 30, 331338, doi:10.1007/s00367-010-0188-9, 2010.

Lelieveld, J., Crutzen, P. J., and Dentener, F. J.: Changing concentration, lifetime and climate forcing of atmospheric methane, Tellus B, 50, 128-150, 1998. 
Miller, C. E. and Dinardo, S. J.: CARVE: The Carbon in Arctic Reservoirs Vulnerability Experiment, Aerospace Conference, 2012 IEEE, 2012.

Murdock, D. G., Stearns, S. V., Lines, R. T., Lenz, D., Brown, D. M., and Philbrick, C. R.: Applications of real-world gas detection: Airborne Natural Gas Emission Lidar (ANGEL) system, J. Appl. Remote Sens., 2, 023518, 023518, doi:10.1117/1.2937078, 2008.

Murtagh, F. and Heck, A.: Multivariate Data Analysis, D. Reidel Publishing Company, Dordrecht, Holland, 1987.

NOAA: GMD Measurement Locations, National Oceanic \& Atmospheric Administration (NOAA), Earth System Research Laboratory, Global Monitoring Division, 2013.

NRC: Verifying Greenhouse Gas Emissions: Methods to Support International Climate Agreements, Committee on Methods for Estimating Greenhouse Gas Emissions, National Research Council (NRC), The National Academies Press, Washington, D.C., 125 pp., 2010.

Petron, G., Frost, G., Miller, B. R., Hirsch, A. I., Montzka, S. A., Karion, A., Trainer, M., Sweeney, C., Andrews, A. E., Miller, L., Kofler, J., Bar-Ilan, A., Dlugokencky, E. J., Patrick, L., Moore, C. T., Ryerson, T. B., Siso, C., Kolodzey, W., Lang, P. M., Conway, T., Novelli, P., Masarie, K., Hall, B., Guenther, D., Kitzis, D., Miller, J., Welsh, D., Wolfe, D., Neff, W., and Tans, P.: Hydrocarbon emissions characterization in the Colorado Front Range: A pilot study, J. Geophys. Res.-Atmos., 117, D04304, doi:10.1029/2011jd016360, 2012.

Platt, U.: Differential optical absorption spectroscopy (DOAS), in Air Monitoring by Spectroscopic Techniques, John Wiley, New York, 1994.

Platt, U. and Stutz, J.: Differential optical absorption spectroscopy: principles and applications, Springer-Verlag, Berlin Heidelberg, 2008.

Press, W. H., Teukolosky, S. A., Vetterling, W. T., and Flannery, B. P.: Numerical recipes: The art of scientific computing, Vol. 3, Cambridge University Press, Cambridge, 2007.

Roberts, D. A., Bradley, E. S., Cheung, R., Leifer, I., Dennison, P. E., and Margolis, J. S.: Mapping methane emissions from a marine geological seep source using imaging spectrometry, Remote Sens. Environ., 114, 592-606, doi:10.1016/j.rse.2009.10.015, 2010.

Rodgers, C. D.: Inverse Methods for Atmospheric Sounding, Theory and Practice, World Scientific, London, 2000.

Rothman, L. S., Gordon, I. E., Barbe, A., Benner, D. C., Bernath, P. E., Birk, M., Boudon, V., Brown, L. R., Campargue, A., Champion, J. P., Chance, K., Coudert, L. H., Dana, V., Devi, V. M., Fally, S., Flaud, J. M., Gamache, R. R., Goldman, A., Jacquemart, D., Kleiner, I., Lacome, N., Lafferty, W. J., Mandin, J. Y., Massie, S. T., Mikhailenko, S. N., Miller, C. E., Moazzen-Ahmadi, N., Naumenko, O. V., Nikitin, A. V., Orphal, J., Perevalov, V. I., Perrin, A., Predoi-Cross, A., Rinsland, C. P., Rotger, M., Simeckova, M., Smith, M. A. H., Sung, K., Tashkun, S. A., Tennyson, J., Toth, R. A., Vandaele, A. C., and Vander Auwera, J.: The HITRAN 2008 molecular spectroscopic database, J. Quant. Spectrosc. Ra., 110, 533-572, doi:10.1016/j.jqsrt.2009.02.013, 2009.
Schneising, O., Bergamaschi, P., Bovensmann, H., Buchwitz, M., Burrows, J. P., Deutscher, N. M., Griffith, D. W. T., Heymann, J., Macatangay, R., Messerschmidt, J., Notholt, J., Rettinger, M., Reuter, M., Sussmann, R., Velazco, V. A., Warneke, T., Wennberg, P. O., and Wunch, D.: Atmospheric greenhouse gases retrieved from SCIAMACHY: comparison to ground-based FTS measurements and model results, Atmos. Chem. Phys., 12, 1527-1540, doi:10.5194/acp-12-1527-2012, 2012.

Schuck, T. J., Ishijima, K., Patra, P. K., Baker, A. K., Machida, T., Matsueda, H., Sawa, Y., Umezawa, T., Brenninkmeijer, C. A. M., and Lelieveld, J.: Distribution of methane in the tropical upper troposphere measured by CARIBIC and CONTRAIL aircraft, J. Geophys. Res.-Atmos., 117, D19304, doi:10.1029/2012jd018199, 2012.

Stutz, J., Oh, H. J., Whitlow, S. I., Anderson, C., Dibbb, J. E., Flynn, J. H., Rappengluck, B., and Lefer, B.: Simultaneous DOAS and mist-chamber IC measurements of HONO in Houston, TX, Atmos. Environ., 44, 4090-4098, doi:10.1016/j.atmosenv.2009.02.003, 2010.

Thorpe, A. K., Roberts, D. A., Bradley, E. S., Funk, C. C., Dennison, P. E., and Leifer, I.: High resolution mapping of methane emissions from marine and terrestrial sources using a Cluster-Tuned Matched Filter technique and imaging spectrometry, Remote Sens. Environ., 134, 305-318, doi:10.1016/j.rse.2013.03.018, 2013.

Wennberg, P. O., Mui, W., Wunch, D., Kort, E. A., Blake, D. R., Atlas, E. L., Santoni, G. W., Wofsy, S. C., Diskin, G. S., Jeong, S., and Fischer, M. L.: On the Sources of Methane to the Los Angeles Atmosphere, Environ. Sci. Technol., 46, 9282-9289, doi:10.1021/Es301138y, 2012.

Woodwell, G. M., Mackenzie, F. T., Houghton, R. A., Apps, M., Gorham, E., and Davidson, E.: Biotic feedbacks in the warming of the earth, Climatic Change, 40, 495-518, 1998.

Wuebbles, D. J. and Hayhoe, K.: Atmospheric methane and global change, Earth-Sci. Rev., 57, 177-210, doi:10.1016/S00128252(01)00062-9, 2002.

Wunch, D., Wennberg, P. O., Toon, G. C., Keppel-Aleks, G., and Yavin, Y. G.: Emissions of greenhouse gases from a North American megacity, Geophys. Res. Lett., 36, L15810, doi:10.1029/2009g1039825, 2009. 